\title{
El método abierto de coordinación en la UE. ¿Una fórmula institucional de evaluación?
}

Vicente Pérez Menayo*

Palabras clave: Evaluación institucional, políticas europeas, nueva gobernanza, cooperación intergubernamental.

\section{El buen gobierno europeo: de ciegos y elefantes}

\subsection{Del neofuncionalismo a la gobernanza}

El propósito de este trabajo está motivado tanto por un interés teórico como por una aportación empírica sobre la instrumentación de una nueva forma de gobernanza europea: el Método Abierto de Coordinación (en adelante $\mathrm{MAC}$ ). Se trata de comprender mejor el papel de las instituciones comunitarias y de los Estados miembros (en lo sucesivo EEMM) en el proceso de construcción europea, señalando los posibles efectos normativos de los medios de acción «propiamente políticos». El autor de este trabajo ya ha tratado recientemente, desde una perspectiva descriptiva, los aspectos empíricos de aplicación del MAC al ámbito social (Pérez Menayo 2005). En esta ocasión se trata, además, de completar el estudio del MAC desde un punto de vista doctrinal, a la luz de los nuevos enfoques que intentan explicar el proceso complejo de integración europea, entre otros, desde una perspectiva cognitiva, es decir, mediante dispositivos para compartir conocimientos, el aprendizaje mutuo y el intercambio de experiencias. Asimismo, se trata de contestar al interrogante de si el MAC representa un nuevo modelo de evaluación institucional en la UE.

Un artículo de Dür y Mateo (2004) relativo a la literatura más reciente sobre la construcción europea, recordaba que, en 1972, Donald Puchala comparó a los investigadores de la integración europea con hombres ciegos: cada uno de ellos, palpando sólo una parte de un elefante, creía poder describir el animal completo, y aunque todos tenían un conocimiento limitado y distinto del animal, iniciaron una discusión sobre su forma. Esta analogía, podía explicar el debate, un tanto ciego, entre el neofuncionalismo y el intergubernamentalismo, las dos teorías más relevantes de la integración europea en los años sesenta. Treinta años más tarde, la literatura sobre la arquitectura institucional europea ha cambiado fundamentalmente y ha derivado en el surgimiento de nuevos en-

* Consejero Técnico de la Subdirección General de Relaciones Sociales Internacionales del Ministerio de Trabajo y Asuntos Sociales. 
foques teóricos como son el neoinstitucionalismo, la gobernanza y la europeización. Cada uno de ellos responde a objetivos distintos. En primer lugar, el neoinstitucionalismo parece útil a la hora de explicar el rol de las instituciones en el proceso de integración. En segundo lugar, el concepto de la gobernanza (utilizaremos indistintamente el término «buen gobierno») intenta mostrar la complejidad del sistema político de la UE y cómo los actores políticos responden a ésta. En tercer lugar, la literatura sobre la europeización trata de explicar cómo el proceso de integración influye en los EEMM en el ámbito doméstico (Dür y Mateo 2004: 1-6).

Estos nuevos enfoques se concentran en explicar aspectos particulares del proceso de integración en vez de debatir, como hombres ciegos según la analogía de Puchala, qué enfoque explica mejor el elefante. La característica más importante de los nuevos enfoques es que no son contradictorios entre sí, sino más bien complementarios, puesto que la utilización de uno no es excluyente de los demás (Dür y Mateo 2004: 28-29). Y es precisamente este enfoque sistémico el que puede ser más adecuado para las pretensiones de este trabajo.

\subsection{Los «nuevos métodos de gobernanza» y el MAC}

El concepto de gobernanza ha despertado un gran interés entre el mundo académico y político, como resultado de las transformaciones causadas por la globalización, y forma parte de los debates en torno a la reforma del buen gobierno europeo como un objetivo estratégico de la UE. Con él se designan «las normas, procesos y comportamientos que influyen en el ejercicio de los poderes en el ámbito europeo, especialmente desde el punto de vista de la apertura, la participación, la responsabilidad, la eficacia y la coherencia» (Comisión Europea 2001b).

Los estudios sobre el buen gobierno en la UE se centran en dos cuestiones interrelacionadas. En primer lugar, la UE es entendida como un sistema político con distintos niveles (subnacionales, nacionales y supranacionales) en el que muchos actores intentan influir en los procesos políticos (Hix 1998, cit. por Dür y Mateo 2004; Cram 2001). De ahí que esta rama de investigación se llame gobernanza multinivel, en la cual podemos identificar la simple cooperación intergubernamental. En segundo lugar algunos autores han estudiado, más recientemente, lo que denominan los modos o métodos de gobernanza: el método comunitario tradicional, basado en los conceptos de juspositivismo y federalismo funcional, que organiza la adopción de decisiones en el seno del «triángulo institucional» constituido por la Comisión, el Consejo de Ministros y el Parlamento Europeo; el método del dialogo social (art. 138 del Tratado de la Comunidad Europea, en adelante TCE), el método abierto de coordinación y el benchmarking (Telò 2001).

Para los fines de este artículo, entre los diversos usos del concepto de nueva gobernanza retenemos, además, el que dan aquellos autores que la conciben no sólo como un mecanismo de regulación, sino también como un proceso de aprendizaje colectivo basado en la coordinación. En este sentido, algunos autores han visto en el desarrollo del MAC los prolegómenos de nuevas formas de «intercambio de conocimientos» fundadas en las observaciones empíricas (Jacobsson y Vifell 2003).

La literatura sobre los modos de gobernanza (Scharpf 1988 y 2000) trata de explicar cómo el sistema político de la UE, a pesar de su complejidad, puede responder a nuevos desafíos sociales, económicos y tecnológicos mediante nuevos modos de buen gobierno que ayudan a evitar los bloqueos del sistema político de la UE. Así, para Scott y Trubeck (2002: 1-18), los nuevos modos de buen gobierno resultarían de seis factores:

- la complejidad creciente de los problemas a tratar;

- un entorno presidido, cada vez mas, por la incertidumbre;

- la diversidad de los contextos nacionales que dificultan toda solución uniforme (con una UE ya de 27 miembros); 
- la evolución general de las prácticas administrativas y jurídicas;

- las obligaciones impuestas a las instituciones comunitarias por defecto de las competencias legales; y, finalmente,

- el principio restrictivo de subsidiariedad (art. 5 TCE).

Por otra parte, la literatura no sólo ha estudiado dónde y cómo se han utilizado los nuevos modos de gobernanza en la UE, sino que también ha intentado responder a la pregunta de si éstos son más eficaces, eficientes y democráticos que los tradicionales. De ahí que haya surgido mucha literatura empírica, pero no un cuerpo teórico con una lista de hipótesis y una metodología propia. Este último argumento es aplicable al MAC en su conjunto, en donde, además, los debates se han limitado a un círculo de iniciados no exento de posiciones dogmáticas y académicas, sin extraer las enseñanzas de su funcionamiento efectivo, como veremos a lo largo de las páginas que siguen. La integración europea no está gobernada solamente por el método comunitario tradicional, sino que se alimenta, a su vez, de los efectos de la integración producidos por los nuevos modelos de gobernanza. Es decir, las policy-making europeas han evolucionado hacia la nueva gobernanza, en donde se sitúa el MAC (Bruno et al. 2004).

El «programa ambicioso de integración política», iniciado por el Tratado de Maastricht, revela las insuficiencias del método comunitario para asumir plenamente su papel de motor de la integración. Al lado del pilar que representa el acervo comunitario, se vuelve al método intergubernamental, que asigna un papel relevante a los EEMM. Esta vuelta al intergubernamentalismo, que podría ser percibida como un retroceso con relación a los instrumentos de integración elaborados por el derecho comunitario, se ha convertido sin embargo en el único medio para desbloquear estos, y otros, «pedestales» de soberanía nacional (Pérez Menayo 2003a y b y 2005). Hay que precisar que el MAC no se configura como un método que se sitúa a medio camino entre el método comunitario y el método intergubernamental, como un modo de conciliación entre ambos métodos. Al contrario, apunta un paso cualitativo, alejándose claramente en el plano conceptual de los métodos clásicos de la integración. En fin, puede ser útil rememorar el dilema de los años 1990: «ampliación o profundización». Ya se trate de una apuesta real o de un «falso dilema», lo cierto es que una UE a 27 miembros, y no demasiado tarde a 30, necesita revisar sus instrumentos de acción. Y es en este contexto en el que aparece el MAC (Georgopoulos 2005: 1-3).

Así, según esta literatura, entre los nuevos métodos de gobernanza en la UE, se encuentra el MAC (Eberlein y Kerwer 2002; Héritier 2002, cit. por Dür y Mateo 2004; Knill y Lenschow 2003). Telò (2001: 4), ha establecido una tipología de las formas de gobernanza en función de los modos de regulación, cuya multiplicación ha observado a lo largo del último decenio en la Comunidad Europea: la gobernanza por persuasión, fundada en el recurso al experto, la gobernanza por consulta, que ha abierto específicamente el diálogo social, inscrito en el Tratado de Maastricht (Título XI del TCE), o la gobernanza por la difusión de las mejores prácticas, formalizada por primera vez en las Conclusiones del Consejo Europeo de Lisboa de marzo de 2000 con la introducción del MAC. Se trata de dar valor al abanico muy variado de formas disponibles de regulación y el desafío que supone una gestión dinámica de las diversidades nacionales y regionales, que se traducen tanto al ámbito de las prácticas descentralizadas como en los límites establecidos por los Tratados con relación a la aplicación del método comunitario (Telò 2001). Y es aquí donde se sitúa la utilidad del MAC, como un intento de encontrar un camino intermedio entre la armonización de estándares y el reconocimiento mutuo con el objetivo de utilizar las mejores prácticas posibles adaptándolas a las circunstancias locales.

Ante esta situación, el enfoque de la coordinación de las políticas a través del MAC tiene cabida en la UE para resolver, de manera conjunta, los aspectos que están condicionando la construcción del mercado único mediante la lógica del minimo común denominador que rige las negociaciones internacionales clásicas. Se apela a un marco deliberador y decisional más flexible y voluntarista en contraposición al control vertical privilegiado por el viejo estilo del paradigma jerárquico de gobernanza: control, marco de decisión arriba-abajo y uniformidad (Everlein y Kerwer 2002: 1). 
Se ofrecen, entre otros, dos escenarios para valorar la importancia del MAC. Éste pretende limitar la divergencia, e incluso producir un grado de convergencia en algunos casos. Para la identificación doctrinal del MAC interesa matizar que la convergencia concierne a las realizaciones, a los resultados (performances) y no forzosamente a las políticas ejecutadas por los EEMM. Por otra parte, en este método no hay sanciones, sino una coordinación voluntaria. Además, es necesario resaltar que la definición del MAC no está integrada en el Tratado, y que no hay ninguna referencia explícita a él en ningún artículo del mismo, a pesar de los intentos de diversos grupos de trabajo de la reciente Convención Europea para la formulación de un nuevo Tratado por el que se constituye una Constitución para Europa sobre el que se cierne una franja de incertidumbre. En definitiva, con el MAC se produce una formalización progresiva de procedimientos que tienden a disciplinar los procesos de europeización articulando instrumentos informativos y comunicacionales, acompañados de otros convencionales e indicativos, o incluso legislativos y reglamentarios, en su caso (Lascoumes 2003: 388).

\section{El MAC: entre la«coordinación vinculante» y la «cooperación amortiguada»}

\subsection{Dispositivos no obligatorios de buen gobierno}

Entre la pluralidad de modelos teóricos citados que buscan acotar la naturaleza compleja de la integración europea, destacan ciertos rasgos distintivos. La mayoría de los autores insiste en el carácter suave (soft) de estos procesos no coercitivos que se apoyan sobre la voluntad de los actores de acordar, para la deliberación colectiva, normas de procedimiento, modos de regulación y objetivos políticos comunes, preservando la diversidad de las soluciones nacionales. Para De la Rosa (2005), el soft law ha sido aprehendido en el derecho comunitario desde el ángulo de sus efectos normativos indirectos unas veces a través de su utilización en el razonamiento del juez comunitario, otras por sus efectos en términos de obligaciones figuradas.

En efecto, el recurso al soft law, o «norma suave», no es nuevo en el derecho comunitario. Los actos no decisorios previstos por el TCE constituyen una expresión bien conocida. Se trata de saber si el MAC, como nuevo instrumento de convergencia, pertenece a esta categoría general e imprecisa. Ahora bien, interrogarse sobre el parentesco entre MAC y soft law supone previamente retener o, al menos, postular una definición del término. Para Imani (2005), el «derecho blando» o las «normas suaves», tienen como finalidad hacer frente a la inadaptación o a la inexistencia de normas. Teniendo en cuenta que no existe una definición exacta del término, se habla a menudo de autorregulación, de reglamentación voluntaria, de correglamentación, o de casi-reglamentación.

Es en esta última óptica de la instrumentación de la acción pública (Lascoumes 2003) en la que cabe enmarcar el MAC como una herramienta que permite materializar y hacer operativa dicha acción pública a escala de la UE. Forma parte de esta nueva generación de dispositivos no obligatorios de buen gobierno los denominados soft law governance (Jacobson 2001), que están influyendo en el fenómeno de la «europeización» como proceso, en comparación con los útiles tradicionales de gobierno (Radaelli 2001). Es decir, como resultante de «presiones adaptativas», ejercidas por el gobierno comunitario, mediante procesos de institucionalización específicos, iniciados y guiados por la Comisión Europea, sobre las «estructuras domésticas» (los EEMM) y a través del proceso de formulación de orientaciones políticas ejercidas al modo intergubernamental.

Ahora bien, a los ojos de un jurista, el elemento que más puede extrañar del MAC es la ausencia de sanción jurídica. Tanto el juez comunitario como el juez nacional no tienen mucho que decir respecto a la aplicación del MAC. El enfoque desafía el positivismo jurídico; en lugar de una sanción jurídica por la violación del derecho 
comunitario, encontramos la evaluación, el intercambio de informacion y el aprendizaje (Poelemans 2004). De la configuración de una Comunidad Europea de derecho, pasamos a una UE como espacio de conocimientos y de experimentación. Los Estados que no ejecutaron sus políticas en concordancia con las líneas directrices emanadas del Consejo de la UE pueden ser destinatarios de recomendaciones, como lo demuestran las áreas formalizadas del MAC sobre economía y empleo (arts. 99 y 128 TCE), a las que haremos mención en el próximo apartado. Sin embargo, el autor no sabría sostener que estas recomendaciones, instrumentos políticos, pueden equivaler al carácter solemne o a los efectos de una condena del Estado ante el juez comunitario, o incluso delante de las jurisdicciones nacionales.

En estas condiciones, podemos afirmar que el MAC constituye una forma de soft law, sin duda entre los más prometedores. Seguramente no es fruto del azar que estos modos alternativos de regulación aparezcan en dominios donde es particularmente difícil de convencer a los EEMM a que renuncien a su competencia en favor de una competencia comunitaria, mientras que, a su vez, la convergencia de las políticas nacionales se revela indispensable para el avance de la integración europea (Georgopoulos 2005).

\subsection{Procesos de coordinación basados en el Tratado y nuevas formas de coordinación abierta}

Otro aspecto que habría que destacar es si cuando hablamos de MAC, estamos en presencia de soft law o de simple soft cooperation («cooperación suave» o «amortiguada»). No se trata únicamente de un aspecto puramente semántico, aunque como decía Confucio «cuando las denominaciones están en orden, el mundo mismo lo está también», sino más bien de identificar si este nuevo concepto se inscribe en el proceso de desarrollo de la adopción de decisiones en la UE o, por el contrario, constituye un retroceso en los procesos de decisión comunitaria (Imani 2005). Para Degryse y Pochet (2000), la Cumbre de Lisboa habla de «método abierto de coordinación», y no simplemente de cooperación (intercambio de experiencias y de buenas prácticas, con estudios e intercambios de información). Sin embargo, el MAC, aplicado a las formas de coordinación inscritas en el TCE, implica el establecimiento de líneas directrices estratégicas, la fijación de puntos de referencia, el establecimiento de objetivos y la puesta en marcha de un sistema de seguimiento para evaluar los progresos por medio de una revisión por grupos de pares, o peer review.

Como señala el grupo interservicios de la Comisión Europea sobre gobernanza (Coyne y Pierini 2001), con la entrada de la UE en una fase de integración denominada «activa», los procesos de coordinación de las políticas nacionales, identificadas bajo la denominación de MAC, se sitúan entre estas nuevas formas de acción colectiva que pretenden la compatibilidad, la coherencia o la convergencia de las políticas públicas nacionales. Ocupan una situación intermedia entre una lógica de pura integración legislativa y una lógica de simple cooperación (Tabla 1). La práctica reciente demuestra que pueden ser instrumentos efectivos de integración europea. Muestran cómo el «dinamismo comunitario» no se manifiesta solamente a través del derecho originario de los Tratados, sino que, a menudo, nace de prácticas que encuentran acomodo en las «zonas grises» de sus textos, cuyas revisiones posteriores acaban por codificar. Este es el caso del MAC, cuyas fuentes de inspiración se encuentran previamente en los Tratados de Maastrich (en materia de política económica) y de Ámsterdam (para la política de empleo), y que se consagra en el Consejo Europeo de Lisboa (2000).

Por tanto, el MAC se revela como un instrumento de integración comunitaria (entre otros). Así, puede ser asociado y articulado, para un mismo aspecto y en los límites de los tratados, a otros instrumentos de acción comunitaria, incluido el enfoque legislativo clásico. Sin embargo, no constituye una alternativa competitiva a este último ni tiene por vocación reemplazarlo, mas bien complementarlo (Convención Europea, Grupo Gobernanza Económica 2002: 15). 


\section{TABLA 1}

Formas de cooperación y de coordinación en la UE

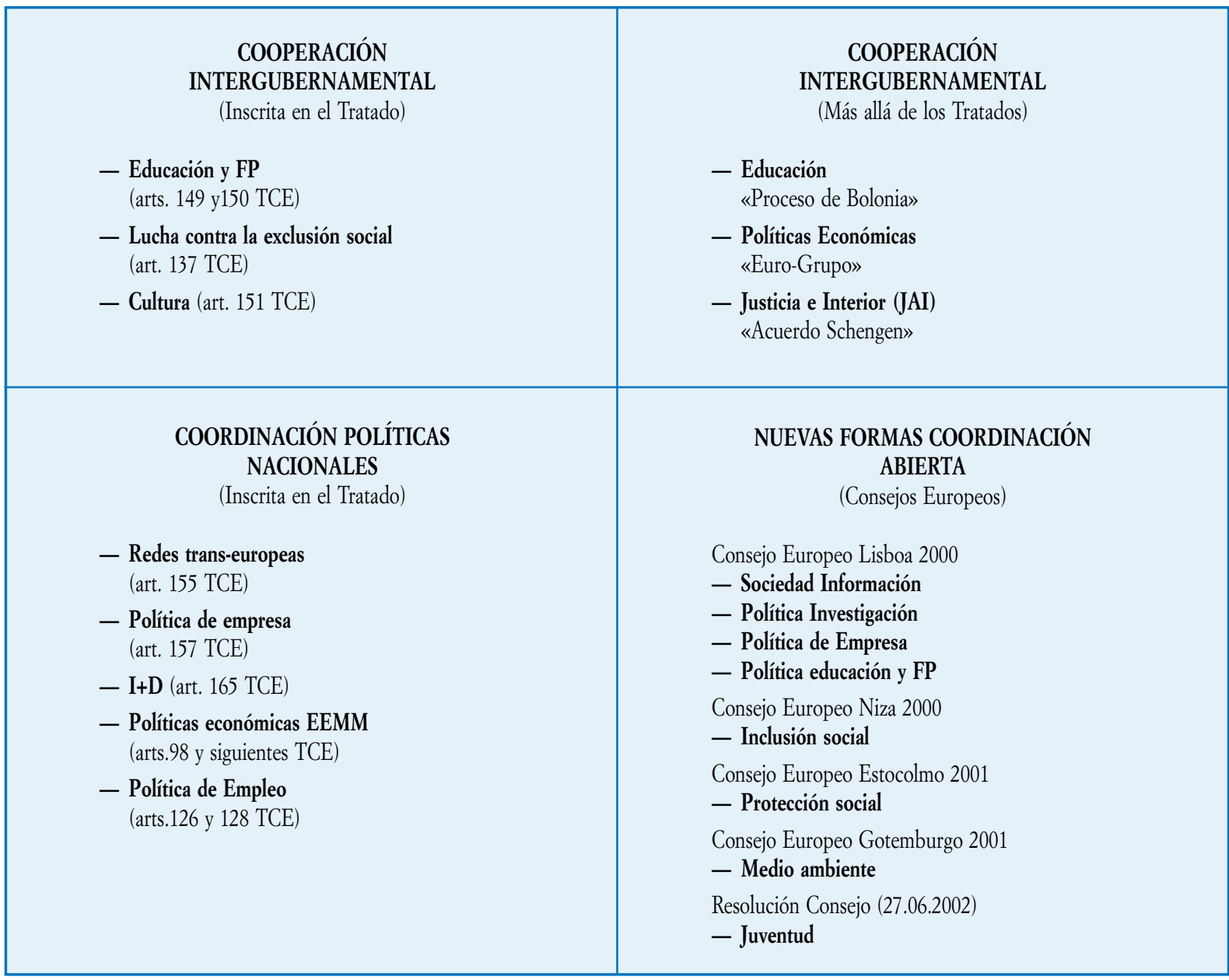

Fuente: Elaboración propia sobre la base de Convención Europea, Grupo sobre Gobernanza Económica (WD 15, 17.08.2002) y Grupo Interservicios de la Comisión Europea sobre Gobernanza (Coyne y Pierini 2001).

El Tratado dota a la Comunidad y a los EEMM de dos procesos específicos de coordinación en el ámbito socioeconómico:

- Las Orientaciones Generales de Política Económica (en adelante GOPEs), son el instrumento global de coordinación de la política económica en la UE y marcan las directrices políticas para la dimensión económica. El objetivo de buscar la coherencia de las políticas nacionales se inscribe en el Tratado según la fórmula: «los EEMM consideran sus políticas económicas como una cuestión de interés común» (art. 99 TCE). Se persigue especialmente a través de la ejecución de un sistema de coordinación económica, las GOPEs, que reposa esencialmente sobre el principio de la definición periódica de objetivos y sobre la evaluación entre homólogos (peer review).

- Las Directrices sobre el Empleo (art. 128 TCE), establecen orientaciones más específicas para las políticas de empleo y sociales en la UE y los EEMM, basadas en instrumentos de vigilancia de la política de empleo y dentro del marco de las GOPEs. Los participantes en la coordinación no convergen necesariamente hacia un modelo único o de métodos comunes; más bien se trata de objetivos idénticos que pue- 
den ser alcanzados según modalidades y con medios diferentes. Es el ejemplo por excelencia del proceso de coordinación establecido en el marco de la Estrategia Europea para el Empleo (Consejo Europeo de Luxemburgo 1997; Capítulo VIII del TCE).

Tales procedimientos de coordinación son obligatorios y permiten a las instituciones de la UE dirigir recomendaciones a los EEMM e incluso imponer sanciones a dichos estados que no respeten las directrices conjuntamente marcadas.

Teniendo en cuenta la experiencia adquirida con estos dos procesos, la Cumbre de Lisboa estableció el mecanismo más generalizado de coordinación en los ámbitos en los que las competencias recaen principalmente en los EEMM. Estas políticas han permitido instrumentar un método de coordinación más abierto a la diversidad nacional, cuyo ejemplo más desarrollado, desde el punto de vista socioeconómico, es la Estrategia Europea para el Empleo antes citada. Ésta introduce el MAC con carácter previo a su formalización en la Cumbre de Lisboa, que se apoya, según la Comisión, en cinco principios clave:

- Subsidiariedad: El método establece un equilibrio entre la coordinación, en el ámbito de la UE, de la definición de objetivos, del examen de los resultados y de las responsabilidades de los EEMM para decidir el contenido preciso de las acciones. La definición de los medios y las condiciones en las que se ejecutan los programas y las políticas queda en manosde los EEMM, que son, en gran medida, responsables de sus políticas.

- Convergencia: El método busca lograr resultados acordados en común a través de una acción concertada, donde cada Estado miembro contribuya a mejorar el resultado de la Unión.

- Gestión por objetivos: El éxito reposa en la utilización de medidas de referencia y de objetivos cuantificados para asegurar un seguimiento y una evaluación de los progresos alcanzados. El progreso en la realización de estos objetivos se define en términos de indicadores cuantitativos y/o cualitativos. Así, los objetivos e indicadores hacen transparentes los resultados de las políticas y, por lo tanto, abiertos al escrutinio público.

- Vigilancia multilateral: El examen de las políticas nacionales permite la evaluación y la comparación de los progresos alcanzados, y la identificación de las mejores prácticas en los EEMM. Esto crea una presión «por los pares» (peer review) para mejorar la calidad y la eficacia de las políticas. El intercambio de experiencias y la presión «por los pares» permite estimular el debate político y mejorar la eficacia de las políticas.

- Enfoque integrado: Las directrices, los objetivos comunes, etc. no pueden ser obtenidos por medio de acciones aisladas y dispersas: exigen una acción coherente y concertada sobre un amplio abanico de políticas y medidas (Comisión Europea 2005a y b).

Estos principios pueden ser de validez general para enmarcar el MAC en un contexto más amplio de aplicación a otras políticas. Así, Borrás y Jacobsson (2004) distinguen, por su parte, seis características principales del $\mathrm{MAC}$, algunas coincidentes con los principios esbozados por la Comisión, y otras que son las que analizamos a continuación: el voluntarismo, la subsidiariedad, la flexibilidad, la participación, la integración de las políticas y la integración a varios niveles. Asimismo, las redes de regulación ayudan a evitar el bloqueo del sistema político de la UE conectando los distintos niveles de decisión (Sabatier 1998, cit. por Mateo y Dür 2004; Radaelli 1999).

- En cuanto al primer principio, mediante el cual la dinámica del MAC reposa esencialmente en la cooperación voluntaria, refleja las preocupaciones específicas de cada comunidad política y la satisfacción profesional de los actores que desempeñan papeles de primer plano. En este marco, toda tentativa de con- 
trol exterior corre peligro de ser percibida como una interferencia ilegítima. En algunos casos, la experiencia ha mostrado que las líneas directrices elaboradas por el Consejo Europeo no siempre son ejecutadas en debida forma por los niveles inferiores de la jerarquía (Collignon et al. 2004). Estos mismos autores, reconocen otras características claves del MAC:

- Su flexibilidad: El MAC no pretende definir objetivos únicos, sino que se esfuerza por establecer «líneas directrices» que cada Estado miembro traducirá en planes de acción específicos con arreglo a su propia situación. Este deseo de reflejar el contexto nacional en el cual las políticas deben ser puestas en ejecución se explica fácilmente por la naturaleza de los ámbitos políticos afectados y, además, hace la distinción entre, por ejemplo, el trabajo en el entorno europeo y el trabajo realizable en el marco de la OCDE $\mathrm{u}$ otras organizaciones internacionales.

- La naturaleza descentralizada del proceso: El impulso no se considera que deba venir de arriba, sino de un trabajo en equipo que reúne «la Unión, los EEMM, las colectividades regionales y locales, al igual que los interlocutores sociales y la sociedad civil» (Consejo Europeo de Lisboa, apartado 37 de las Conclusiones), poniendo el énfasis en la naturaleza «abierta» del nuevo método, que desarrollaremos mas adelante.

- Ubicar procedimientos de rutina mediante el fomento del intercambio en común de conocimientos, comprendida la definición de las líneas directrices y de los indicadores, un control periódico de los informes nacionales y la búsqueda de las mejores prácticas. Los representantes públicos nacionales, actores claves de este proceso, deben hallarse en situación de identificar los puntos fuertes y los puntos débiles de sus planes de acción comparando sus resultados con los de sus homólogos.

- La ausencia de obligaciones formales: Al estar las líneas directrices privadas de carácter obligatorio, el proceso de evaluación por los pares pretende estimular los intercambios de información. En la práctica, a principios de cada año, la Comisión elabora un informe (de síntesis, para el Consejo Europeo de primavera) que evalúa los progresos del conjunto de los países hacia la realización de los objetivos. Con el fin de asegurar el éxito de la nueva estrategia, se centra sobre la emulación entre los EEMM (benchmarking), más que sobre mecanismos clásicos de control comunitario. La presión por los homólogos es considerada como compensatoria de los poderes limitados otorgados a la Comisión en la mayoría de los campos afectados. La elección del MAC como un instrumento no obligatorio ilustra un compromiso político que se ejerce a dos niveles: de una parte entre los actores económicos y sociales y, de otra, entre los EEMM, la Comisión y el Consejo de Ministros. Sin embargo, hay autores para los que no es muy exacto afirmar que el MAC está privado de toda obligación. La sanción está presente, pero está disimulada detrás del «parapeto» de la concertación política. Las recomendaciones previstas en el marco de las políticas económicas y en el marco de la política de empleo, ya contienen un aspecto «pedagógico», incluso una forma de «reproche», una suerte de sanción en sí (Georgopulos 2005).

Así, en el marco de la Estrategia de Lisboa, ha quedado establecido un «nuevo ciclo»: el Consejo Europeo examina cada primavera el estado de las reformas que se acordaron en marzo de 2000. Tras evaluar detalladamente la aplicación de directrices previamente adoptadas y teniendo en cuenta las orientaciones emitidas por el Consejo Europeo de primavera, la Comisión elabora recomendaciones. Estas recomendaciones son discutidas por las formaciones pertinentes del Consejo, que adoptan conclusiones específicas. No obstante, el MAC no sigue plenamente este modelo ideal en las demás áreas en las que se está aplicando, distintas a las de la política economica y de empleo:

- Una parte de la coordinación no está apoyada por informes nacionales de aplicación.

- A diferencia de las GOPEs y las Directrices sobre el Empleo, no existen recomendaciones específicas de la Comisión. 
- A través del MAC, los EEMM acuerdan objetivos comunes, con calendarios y objetivos específicos, que deben traducirse en acciones nacionales y regionales.

- La Comisión supervisa el desarrollo de estas acciones con indicadores cuantitativos y cualitativos, parámetros y una evaluación comparativa.

- Los EEMM tienen que presentar informes periódicos a la Comisión.

En cuanto a esta última característica, conviene señalar que a raíz del Consejo Europeo de Barcelona (2002) se insta al Consejo y a la Comisión a que racionalicen los procesos y mejoren los métodos de trabajo de la Unión. Así, se establecerá, a partir de 2006, un nuevo procedimiento de «sincronización (streamlining) de los procesos de coordinación de las políticas», que establecerá los principios y las principales características para una mejor sistematización de los procedimientos de coordinación de las políticas y adecuará el horizonte temporal de los distintos procesos (GOPEs, empleo, inclusión social, protección social...), con calendarios integrados, para ganar coherencia (Consejo UE 2002; Comisión 2005c).

Desde una perspectiva neofuncionalista de la integración europea, la inscripción en la agenda europea de determinadas áreas, hasta la Cumbre de Lisboa poco presentes en el contexto de decisión comunitaria, obliga a plantearse dos aspectos clave identificados en el «Libro Blanco sobre la Gobernanza europea» (Comisión 2001b): cómo garantizar que el MAC «añada valor» a los procesos comunitarios existentes y cómo asegurar que se tenga en cuenta el equilibrio institucional.

Sobre la base del análisis de lo señalado hasta ahora, se coincide con el grupo ínter servicios de la Comisión Europea sobre gobernanza (Coyne y Pierini 2001), cuando constatan el efecto de spill-over (o efecto inducido en otras políticas), del método utilizado en materia de coordinación de las políticas económicas de los EEMM insertado en el Tratado en Maastricht, hacia otros dominios como la inscripción en el Tratado de Ámsterdam de un nuevo capítulo sobre el empleo o la decisión política de aplicar el MAC sobre otras políticas estructurales de los EEMM de la Unión (Consejo UE 2000). Asimismo, la definición de la «coordinación como proceso» en el Tratado, permite al MAC adquirir un valor añadido en sí, y ocupar su propia plaza en la arquitectura europea al lado de los instrumentos tradicionales de integración. Con la definición del nuevo método, y la extensión a otras políticas estructurales de los EEMM de los instrumentos forjados por el proceso de coordinación de las políticas económica y de empleo, el efecto inducido del MAC está confirmado.

\section{La formalización del MAC en la Cumbre de Lisboa: «Esperando a Godot»}

\section{1. ¿Un nuevo método?}

En una reciente contribución, el profesor Georgopoulos (2005) recordaba el diálogo final de la obra «Esperando a Godot» del dramaturgo irlandés Samuel Beckett, para referirse a las expectativas surgidas en torno al MAC, del mismo modo que los personajes de la obra, Vladimiro y Estragón, esperan que la llegada del misterioso señor Godot cambiase sus vidas. Y cuando finalmente deciden irse, para volver seguramente al día siguiente, quedan sin embargo inmóviles, contentándose con afirmar que «Mañana todo estará mejor», y que Godot finalmente vendrá. «¿Y si viene?», se pregunta Estragón, «Nos habremos salvado», contesta Vladimiro. Así, Godot se convierte en una especie de consagración de la esperanza. 
La construcción política de la UE es una experiencia única. Su éxito depende de la capacidad de combinar la coherencia, con el respeto de la diversidad y la eficiencia con la legitimidad democrática. Esto requiere la utilización de métodos políticos diferentes en consonancia con las políticas y los respectivos procesos institucionales (Consejo UE 2000). El autor, cada vez que se enfrenta al análisis de la arquitectura europea, siempre se sitúa dentro de la escuela de pensamiento asertivo, es decir de afirmación en lo positivo (en contraposición al pesimismo vital y la angustia indisociable de la condición humana, de la obra de Beckett citada), ya que entiende que en el trabajo cotidiano de la UE, a pesar de su complejidad, siempre se encuentran «soluciones imaginativas» que permiten avanzar en el progreso de la Unión. Y es aquí en donde entra en juego el MAC.

En ausencia de una definición clara y precisa del MAC, tenemos que acudir al Consejo Europeo de Lisboa de 2000. En esta cumbre, el MAC fue presentado como un procedimiento nuevo para facilitar la consecución del ambicioso objetivo estratégico propuesto para dicha ocasión: convertirse en la economía basada en el conocimiento más competitiva y dinámica del mundo, capaz de crecer económicamente de manera sostenible con más y mejores empleos y con mayor cohesión social. Su principal razón de ser es el hecho de que muchos de los objetivos de la estrategia de Lisboa pertenecen a ámbitos en los que la competencia recae en gran parte en los EEMM y, por lo tanto, no puede aplicarse el método comunitario clásico. Pero ¿en qué medida el MAC representa la creación de un nuevo instrumento de buen gobierno comunitario?

Como proceso cognitivo, el MAC apareció en el seno de la UE en los años 90, como método de regulación complementario, o alternativo según alguna doctrina, al método comunitario, tal y como hemos subrayado en el apartado anterior. El Consejo Europeo de Lisboa propuso que se facilitara la aplicación de un «nuevo método abierto de coordinación», que se introdujo «como manera de extender las prácticas idóneas y alcanzar una mayor convergencia en torno a los principales objetivos de la UE» en los ámbitos en los que las competencias de la Comunidad son limitadas. Es coherente con las disposiciones del art. 137 del Tratado, que, en la definición del papel de la Comunidad, establece que ésta «apoyará y completará» las actividades de los EEMM (Cuadro 1).

Lo que sienta la Cumbre de Lisboa es la aplicación generalizada del MAC a diversas áreas. El MAC pretende organizar un proceso de aprendizaje sobre cómo hacer frente a los retos comunes de la economía global de forma coordinada, mientras respeta, al mismo tiempo, la diversidad nacional: «se aplicará un planteamiento totalmente descentralizado de acuerdo con el principio de subsidiariedad, en el cual la Unión, los EEMM, los niveles regionales y locales, así como los interlocutores sociales y la sociedad civil, participarán activamente, mediante distintas formas de colaboración. La Comisión Europea, en conexión con distintos suministradores y usuarios, como los interlocutores sociales, las empresas y las $\mathrm{ONG}$, elaborará un método de evaluación comparativa de las prácticas idóneas para la gestión del cambio» (Consejo Europeo de Lisboa, aptdo. 38 de las Conclusiones de la Presidencia). En definitiva, en lugar de combinar diferentes elementos de los métodos comunitario e intergubernamental, el MAC propone otro camino para la integración europea, mediante una regulación por la cognición y el aprendizaje colectivo. 


\section{CUADRO 1}

\section{DEFINICIÓN DEL MÉTODO ABIERTO DE COORDINACIÓN}

Como manera de extender las prácticas idóneas y alcanzar una mayor convergencia en torno a los principales objetivos de la UE (este método) supone:

- Establecer directrices para la Unión combinadas con calendarios específicos para lograr los objetivos que se fijen a corto, medio y largo plazo;

- Establecer, cuando proceda, indicadores y puntos de referencia cuantitativos y cualitativos cotejados con los mejores que existan y adaptados a las necesidades de los distintos EEMM y sectores como método de comparación de las prácticas idóneas;

- Plasmar estas directrices europeas en medidas de política nacional y regional, estableciendo objetivos específicos y dando los pasos adecuados, sin perder de vista las diferencias nacionales y regionales;

- Organizar periódicamente controles y evaluaciones entre homólogos como procesos de aprendizaje mutuo.

Fuente: Consejo Europeo de Lisboa, aptdo. 38 de las Conclusiones de la Presidencia

\subsection{Naturaleza descentralizada y abierta del método}

El principio de subsidiariedad sigue siendo la base del método que requiere un planteamiento completamente descentralizado, que se explica porque el impulso nace de un trabajo colectivo y pone el acento sobre el carácter abierto del nuevo método (Collingon et al. 2004). Para Telò (2001), es el método el que es abierto, no la coordinación. La coordinación es la que está indicada por los Tratados (cooperación, más rol de la Comisión, etc.). Subrayar el carácter abierto del método requiere insistir sobre:

- La gestión prudente de las diversidades por la combinación delicada entre indicadores comunes y objetivos diferentes en el entorno nacional y regional.

- La apertura a los interlocutores sociales (y a los representantes de la sociedad civil organizada).

- El enfoque hacia las pasarelas de lo comunitario, allí dónde la naturaleza del interés general y el consenso entre los EEMM permite franquear las dificultades. El Consejo de la UE, aclara y matiza, inicialmente, el alcance del MAC en una nota elaborada por la Presidencia portuguesa (Consejo UE 2000) según la cual el MAC no pretende fijar una clasificación general de EEMM en cada política, sino organizar un proceso de aprendizaje a escala europea con el fin de estimular el intercambio y la imitación de las mejores prácticas (benchmarking), y de ayudar a los EEMM a mejorar sus propias políticas nacionales.

- El MAC utiliza, como técnica, la evaluación comparativa de resultados, pero no se reduce a dicha técnica. Crea una dimensión europea mediante la determinación de directrices europeas y fomenta la gestión por objetivos mediante la adaptación de dichas directrices a la diversidad nacional.

- El MAC es un medio concreto para desarrollar la gestión moderna utilizando el principio de subsidiariedad.

- El MAC puede fomentar la convergencia en el interés común y en determinadas prioridades comunes acordadas, al tiempo que respeta las diversidades nacional y regional.

- El MAC debe combinarse con los restantes métodos disponibles en función del problema que haya que abordar. Dichos métodos pueden abarcar desde la integración y la armonización, hasta la cooperación. Como hemos señalado, el propio MAC ocupa una posición intermedia en esta gama de distintos métodos. Es un instrumento más que se suma al conjunto general de métodos existentes. 
Por su parte, la Comisión Europea (2001b) resume las características del método y presenta varios enfoques para su aplicación:

- «El MAC se emplea caso por caso». Ofrece un medio de fomentar la cooperación, intercambiar buenas prácticas y acordar objetivos y orientaciones comunes para los EEMM, a veces con el apoyo de planes de acción o estrategias nacionales (por ejemplo, el empleo, la inclusión social, las pensiones, la asistencia sanitaria y los cuidados de larga duración proximamente,...). Se basa en una evaluación sistemática de los progresos realizados en la materialización de tales objetivos, lo que permite a los EEMM establecer una comparación entre sus respectivos esfuerzos y aprender de la experiencia de terceros.

- En otros ámbitos (por ejemplo la política social o de inmigración) el método «se aplica en paralelo al enfoque legislativo» y basado en programas comunitarios; en otros, aporta un valor añadido al ámbito europeo allí donde existe escaso margen para soluciones legislativas.

En un sentido general, el MAC podría ser concebido como una parte de los «procesos transnacionales de política pública» que están enraizados en las instituciones políticas que están menos claramente definidas y son mucho menos coercitivas que aquellas de un Estado tradicional. Se concibe como un instrumento que añade valor a la integración europea, allí donde hay poco margen para las soluciones legislativas. Un ingrediente clave del enfoque del MAC es la utilización de un método descentralizado de coordinación en el que varios actores juegan un papel activo respecto al principio de subsidiariedad, lo que le confiere su carácter abierto. La emergencia de este nuevo método coincide con una dificultad real para definir una nueva agenda de propuestas legislativas en aquellos sectores en donde se tiene que actuar o está ya aplicándose. El autor alberga la percepción de la tendencia hacia una menor cantidad de medidas de obligatoriedad legal que emanan de la UE después de la entrada en vigor del Tratado de Ámsterdam.

Esto corrobora la posición de algunos autores que ven que el MAC puede servir de sustitutivo del método legislativo tradicional. También resulta del análisis, que el MAC y la legislación comunitaria clásica no son instrumentos alternativos de integración, sino que pueden revelarse complementarios. Para la Comisión Europea (2001b: 428) «la utilización de este método no debe romper el equilibrio institucional ni diluir la realización de los objetivos comunes recogidos en el Tratado». El MAC debería completar, nunca sustituir, la acción comunitaria. En todo caso, el carácter alternativo del MAC no debe ser aprehendido como un dilema, sino más bien como una cuestión de coexistencia (si es posible armoniosa), entre los dos métodos de regulación, comunitario y de coordinación abierta, distintos pero compatibles.

\subsection{Implicación de los actores, transparencia y legitimidad democrática}

El carácter innovador del MAC requiere ser matizado. Además de sus relaciones innegables con el método comunitario, se han suscitado los interrogantes habituales en el debate científico y político de la integración europea: eficacia, seguridad jurídica y legitimidad. Aunque sea todavía prematuro extraer un balance definitivo del MAC, su éxito dependerá esencialmente de su capacidad de abastecer de respuestas convincentes a estos postulados (Georgopoulos 2005). La aproximación abierta y descentralizada del MAC, que se acaba de reflejar, plantea, por fin, las cuestiones de la implicación de los actores afectados a todos los niveles en los diferentes procesos: la transparencia de los procedimientos, la accesibilidad de la información y la participación democrática. Sin embargo, surge el siguiente interrogante: ¿Cómo organizar la aplicación del MAC en los diferentes ámbitos de las políticas?

El análisis comparativo de determinados procesos de coordinación de las políticas nacionales en el entorno europeo permite deducir elementos interesantes desde el punto de vista de la legitimidad democrática. A continuación se profundiza en el rol de los actores principales involucrados en la ejecución del MAC: 
- El Consejo Europeo, de manera regular, guía y evalúa los resultados que logre el MAC en sus diferentes ámbitos. Esto exige dos capacidades diferentes de los miembros del Consejo Europeo: definir orientaciones generales para los diferentes ámbitos políticos a fin de organizar el trabajo como preparación y seguimiento de las diferentes formaciones del Consejo; y garantizar su aplicación a escala europea y nacional. Por tanto, el Consejo Europeo es hoy la instancia central de impulso político en el gobierno de la UE y se ha convertido en un auténtico órgano de decisión política en la definición de las grandes orientaciones estratégicas y en el control de su ejecución. Esta evolución es explícita en los ámbitos cubiertos por el MAC.

- En cuanto al Consejo de Ministros, está llamado a jugar un papel «gubernamental» en el marco del MAC. En efecto, los ámbitos de intervención del Consejo se han multiplicado mediante la ampliación progresiva de sus funciones en los sectores cubiertos por los procesos de coordinación, como complemento a su función legislativa tradicional. Esto se ha traducido en la multiplicación de formaciones y de recintos preparatorios, especialmente los comités del Consejo. Así, el proceso de formulación de orientaciones políticas se ejerce desde el modo intergubernamental en donde se inscriben los diferentes comités constituidos por los representantes nacionales (el Comité Económico y Financiero, art.114 TCE; el Comité de Política Económica, art. 272 TCE; el Comité de Empleo, art. 130 TCE; y el Comité de Protección Social, art. 144 TCE), en cuyo seno se elaboran, junto a la Comisión, los objetivos comunes y los indicadores, que posteriormente son adoptados por el Consejo de Ministros correspondiente, y que se convierten, además, en el escenario de la evaluación entre pares (peer review).

- Por lo que se refiere a la Comisión, también asistida por comités, juega un papel central, de impulso y de catalizador en el marco del MAC mediante la presentación de propuestas de líneas directrices europeas y de grandes orientaciones, recomendaciones, en su caso, la organización del intercambio de las mejores prácticas, las propuestas de objetivos comunes y de indicadores, el apoyo y la gestión del seguimiento de los procesos y la evaluación realizada por la propia Comisión y por los homólogos. Las prácticas de la Comisión se han adaptado bastante rápidamente, ya que el MAC, confía a la Comisión un papel central en las fases diversas del proceso de coordinación, de comparación y de evaluación de las prácticas nacionales (Telò 2001). A fin de cuentas, la Comisión tiene un papel importante que hay que jugar en la recopilación y en la difusión de las informaciones vinculadas a la ejecución del MAC. Es a partir de estos elementos que será operada la evaluación de las políticas nacionales, de las que dependerá la pertinencia de las enseñanzas extraídas (Hodson y Maher 2001)

- El Parlamento Europeo está presente de manera limitada, y no sistemática, en los nuevos procesos de coordinación de las políticas nacionales. El débil papel de esta institución ha generado la propia reacción del Parlamento Europeo. En un dictamen de 2003, el Parlamento Europeo manifestó sus temores ante la falta de control democrático de este procedimiento, que no contempla oficialmente su participación. Este parecer es compartido por el autor ya que resulta paradójico que el MAC se esté aplicando, de facto, a áreas relevantes y sensibles de las políticas públicas europeas, sin implicación formal del Parlamento Europeo, y no se haya reconocido el MAC, de iure, en el proyecto de nuevo Tratado por el que se instituye una Constitución para Europa, mediante una disposición horizontal que definiera el nuevo método y su procedimiento.

- En cuanto a los Parlamentos nacionales, en tanto que órganos de control y de legitimación democrática de las políticas nacionales aprobadas en el marco del MAC, se ha desarrollado una mayor implicación, especialmente en materia de coordinación de las políticas económicas (Consejo Europeo 1999).

- Respecto a las entidades regionales (Comunidades Autónomas, en nuestro caso), la Cumbre de Lisboa solicitó que fueran asociadas al método. Sin embargo, en la práctica, el MAC se construye sobre la base de una evaluación de la posición nacional de los EEMM: el lugar de las colectividades regionales que la componen no está definida y su organización se deja a la esfera nacional. Esto está siendo parte del problema, especialmente en los países con una fuerte descentralización, como Alemania y España, en donde las regiones disponen de auténticas competencias legislativas y poderes presupuestarios. 
En definitiva, sería exagerado afirmar que el MAC es por definición un factor de traba a la democratización de la adopción de decisiones en el entorno europeo. Al contrario, para algunos autores (Georgopoulos 2005: 15) incluso podría revelarse como un factor de impulso en la búsqueda de una democracia europea reforzada. Además del hecho de que el PE no esté excluido por definición de la puesta en ejecución del MAC (ya que guarda siempre sus prerrogativas de control parlamentario con respecto a las acciones de la Comisión y del Consejo), conviene volver a recordar el carácter «abierto» del MAC y la implicación de más actores que amplían la concepción de la democracia representativa, mediante la concertación con los principales interlocutores sociales, llamados a aplicar la norma europea, y los representantes de la sociedad civil. Ahora bien, el carácter democrático del MAC dependerá de su aplicación concreta. El futuro mostrará si los EEMM y la Unión sabrán dar valor al potencial del MAC en materia de legitimidad democrática (Georgopoulos 2005).

\subsection{La experiencia actual en los diferentes ámbitos políticos}

Se está utilizando un enfoque empírico y flexible para poder desarrollar y adaptar el MAC a los rasgos específicos de cada ámbito político. Así, la aplicación del MAC es diferente en todos los sectores y, en general, se está aún desarrollando mediante el diseño de un procedimiento ad hoc para cada ocasión. Para el Grupo de Alto Nivel sobre la Estrategia de Lisboa (KOK 2004), se ha elegido un método de trabajo único, el MAC, que hace uso de toda la gama de instrumentos comunitarios y que se complementa con nuevos instrumentos de evaluación y con el establecimiento de parámetros, con los que se pretende alimentar la voluntad política necesaria para su impulso.

El número de objetivos políticos sectoriales ha aumentado a lo largo del período 2000-2006. Las presidencias sucesivas de la UE han añadido nuevas políticas para poner el énfasis en reformas económicas, el empleo o el desarrollo sostenible, según los programas y preferencias políticas nacionales. Por supuesto, el papel y la responsabilidad de los EEMM, las instituciones europeas, los interesados e interlocutores sociales, difieren según los ámbitos y las competencias afectadas.

En sentido estricto, no debería considerarse que todos los procesos establecidos en Lisboa pertenecen a la categoría MAC. El nivel de progreso es distinto, y oscila desde el aplicado a la inclusión social, probablemente uno de los más estructurados, hasta el de la protección social, en donde se sigue desarrollando el área de las pensiones, y está surgiendo uno embrionario en el sector sanitario y de cuidados de larga duración. Por último, se está considerando su uso como instrumento para desarrollar políticas en nuevos ámbitos: es el caso del medio ambiente donde se está analizando el recurso a este método. Sin embargo, el MAC podría aplicarse en aquellas materias para las que el Tratado prevé una coordinación de las políticas nacionales sin definir sus modalidades, como las redes transeuropeas (art. 155 del TCE), la política de empresa (art. 157 del TCE) y la investigación y desarrollo tecnológico (art. 165 del TCE). En definitiva, para otros autores (Collignon et al. 2004) la aplicación sin discriminación del MAC, manifiestamente no es la solución óptima.

\section{El lugar del MAC entre los instrumentos institucionales de evaluación}

\subsection{Una concepción europea pluralista de las finalidades de la evaluación}

Con el objetivo de iniciar una vía de enfoque de management, mediante el MAC se abre camino un procedimiento más integrado y directo que regula las relaciones y actividades intergubernamentales mediante principios 
normativos y disposiciones no obligatorias. En vez de pretender la armonización sustancial de las políticas nacionales, este método apuesta por la cooperación entre los EEMM mediante la normalización de sus «modos de actuar». Es, de hecho, el campo operativo de los instrumentos manageriales, que limita los ámbitos de intervención de la acción pública de manera más pragmática y convencional, que reglamentaria o procedimental. Se trata de comprender como la representación de una «buena política» se ajusta a un conjunto, de cuya consecución se vincula el ajuste de las finalidades públicas a las normas emanadas de la formulación del proceso. A través del MAC, la UE delimita lo que es necesario y lo que no es necesario hacer, y define lo que debe ser una «buena política». Ante todo, la formulación del MAC es la ilustración de un compromiso político e institucional (Bruno et al. 2004).

Como es sabido, en sus inicios la evaluación fue concebida como una técnica de racionalización de la decisión pública fundada casi exclusivamente sobre la utilización de métodos cuantitativos. Esta concepción positivista e instrumental se ha revelado teórica y prácticamente insuficiente y, sin estar totalmente recusada, actualmente ha cedido la plaza a otras concepciones, muy diversas en verdad, que tienen en común el considerar rigurosamente la pluralidad de los modos de conocimiento y la diversidad de los modos de interacción entre la cognición y la acción (Perret 2001).

Otro aspecto a tener en cuenta proviene de la diversidad de las posiciones sociales en las cuales se inscribe la evaluación. Es más, el grado de institucionalización de los procedimientos de evaluación interviene aquí como una variable crucial. Esquemáticamente, podemos oponer a una tendencia norteamericana, que hace del evaluador profesional el garante de una deontología específica de la evaluación, una tendencia más europea a la institucionalización de los procedimientos. Así, en el contexto europeo, el desarrollo de la evaluación a menudo tiene un carácter más institucional. Hablamos más de evaluación de las políticas públicas (y no sólo de programas), y de las iniciativas de los poderes públicos que desempeñan un papel decisivo en la emergencia de un campo de prácticas evaluadoras, distintas a la vez del control y otras prácticas de estudio y de búsqueda. La dualidad entre la «investigación evaluativa» (evaluation research) y la «evaluación institucional», integrada en el funcionamiento de los sistemas político-administrativos, es más marcada en el contexto europeo que en los Estados Unidos. Como ha observado Perret (2001), en las conferencias mundiales sobre la evaluación, los investigadores europeos están más atentos a la influencia del contexto político sobre el proceso y las utilizaciones de la evaluación que sus colegas americanos.

Después de decenios de maduración, aquella concepción cuantitativa ha dado paso a una nueva noción en donde la evaluación se considera ahora significativa de una nueva manera de concebir la racionalización de la acción colectiva, ampliando la visión tradicional de las relaciones entre las ciencias sociales y la práctica político-administrativa. Siguiendo de nuevo a Perret (2001), esta visión se ha completado con las evoluciones siguientes:

- En primer lugar, condujo a una revalorización de los métodos cualitativos, fundados sobre la observación «naturalista» de la realidad social (etnosociologia) o sobre el desarrollo de las técnicas de trabajo en equipo (grupos de expertos o de actores). Este razonamiento se apoya en un conjunto de criterios de calidad, sugeridos por Chen (1991, cit. por Perret 2001): utilidad de pertinencia, fiabilidad, objetividad, posibilidad de generalizar los resultados y transparencia. No se trata de negar el poder de objetivación de los datos cifrados, que, entre otras cosas, se prestan mejor a la comparación y a la agregación (globalización de las constataciones parciales), como veremos más adelante mediante el análisis de los indicadores estructurales. Hoy está ampliamente admitido que la evaluación reposa en la utilización conjunta de ambos tipos de informaciones: cuantitativa y cualitativa.

- Además de más cualitativa, la evaluación también se ha vuelto más participativa, en la medida en que la cooperación de los diferentes protagonistas de la política evaluada, y en particular los actores más cercanos al escenario de la evaluación, es una condición de la movilización de los conocimientos concretos que detentan. 
- Una tercera evolución consiste en que progresivamente se ha impuesto una concepción más compleja del impacto social de la evaluación. Sin renunciar a la utilización instrumental de la evaluación, percibimos que su interés principal, en la práctica, es permitir una clarificación (enlightenment) del contexto de la decisión. Y, por otro lado, comenzamos a percibir el hecho de que el conocimiento sobre las condiciones de ejecución y los resultados de una acción pública es un recurso útil para el conjunto de los actores, de ahí el acento puesto sobre la dimensión «formativa» (cognitiva) de la evaluación (la evaluación como proceso de aprendizaje y de movilización).

Esta coexistencia de finalidades y de referencias metodológicas cada vez más diversificadas se traduce en disputas teóricas inevitables y complejas, entre las que se encuentran las relativas a las diferencias entre la «evaluación managerial» y la «evaluación democrática», a la que, de algún modo, se ha hecho referencia en páginas anteriores. Para los objetivos de este trabajo, el concepto de evaluación ha de ser entendido desde una perspectiva multidisciplinar y desde la complementariedad de los métodos cuantitativos y cualitativos. Esto significa que la evaluación se apoya sobre una gran variedad de fuentes de información. Desde que se toma en consideración la diversidad de los modos de inscripción del conocimiento en el funcionamiento de los sistemas de acción y de decisión, los principios metodológicos y deontológicos aplicables al management político y organizacional de la evaluación, cobran más importancia. Por tanto, la profundización de la reflexión sobre el uso social de la evaluación nos conduce a conceder una gran importancia a:

- La búsqueda de un consenso (o más exactamente, a la elaboración de un punto de vista políticamente y socialmente legítimo) sobre la definición del objeto y la formulación de las cuestiones a las cuales la evaluación deberá responder; en el contexto actual de la acción colectiva, una de las principales funciones aseguradas por la evaluación es catalizar la cooperación entre actores públicos autónomos comprometidos en una misma acción (podemos decir que es el «lenguaje de la colaboración» o del «partenariado»).

- La credibilidad de las informaciones utilizadas.

- La legitimidad de las interpretaciones y de los juicios de valor que fundan las conclusiones, las recomendaciones y las proposiciones.

\subsection{El MAC como proceso de evaluación institucional}

Aunque el MAC no ha sido conceptualizado doctrinalmente se puede calificar como «método-proceso» (Setbon y Lascoumes 1996), dentro de la concepción europea de la institucionalización de los procedimientos de evaluación y la influencia del contexto político. Así, el MAC intenta organizar y sistematizar, en forma de procedimientos, los procesos complejos de ajuste recíproco entre el trabajo de las instituciones comunitarias (objetivos comunes, planes nacionales, indicadores, evaluación, etc.) y el rol de los EEMM (saber práctico de los actores-expertos nacionales y de los decidores políticos).

Según una de las definiciones clásicas (Meny y Thoening 1989), una política pública se caracteriza por cinco elementos relacionados entre ellos: un contenido (recursos utilizados para alcanzar los objetivos); un programa (una estructura de acciones relativamente permanentes); una orientación normativa; un factor de coerción (referido al ejercicio de una fuerza legítima); y un conjunto de actores afectados por la política. Hay autores que entienden que no se puede aplicar este marco metodológico completamente ni a las políticas europeas en general, ni al MAC en particular. Por el contrario, si se pone el acento sobre los aspectos cognitivos de las políticas (Muller 2000; Sabatier y Schlager 2000), el MAC se convierte en algo menos extraño al campo de la evaluación institucional de políticas públicas. La mayoría de los expertos recuerda que la evaluación es uno de los elementos constitutivos del MAC y así lo acredita el aptdo. 37 de las Conclusiones del Consejo Europeo de Lisboa: «organizar periódicamente controles y evaluaciones entre homólogos como procesos de aprendizaje mutuo». 
Por su parte, Goetschy (2004) sostiene que los elementos del método sobre el que se apoya el MAC, se inscriben en un movimiento de modernización de políticas públicas, planteado en determinados EEMM, con sus objetivos, su calendario y su «cultura de evaluación». A través de estos elementos se espera, por un lado, acotar mejor el impacto cuantitativo y cualitativo de las decisiones europeas (líneas directrices y objetivos comunes) en los planes nacionales y, por otro, orientar más rápidamente las políticas hacia una mayor convergencia europea. Los instrumentos de gestión inherentes al MAC, que toma prestados del management público moderno, sirven para la profundización en la integración europea y en la eficacia de las políticas nacionales de diversas maneras:

- Estableciendo las obligaciones externas y los objetivos a alcanzar en un horizonte temporal dado.

- Comparando los objetivos y resultados nacionales con los de los países mejor situados sobre la base de una panoplia de indicadores y sometiéndoles a la criba y a la evaluación de un vasto elenco de instituciones europeas a través de informes conjuntos Consejo-Comisión.

- Exponiendo las medidas políticas nacionales a la amenaza potencial de «recomendaciones» de la Comisión Europea y del Consejo de la UE.

Así, el grado de severidad de la evaluación y la firmeza del control por parte de la Comisión, varían según los ámbitos de actuación del MAC y el grado de resistencia política del Consejo, manifestada en el contexto intergubernamental en los distintos Comités anteriormente citados, en donde están representados los expertos y responsables gubernamentales. La tensión entre profundización europea y respeto de las sensibilidades nacionales se inscribe en el centro del MAC (Goetschy 2004).

Para Degryse y Pochet (2000), el MAC implica el establecimiento de líneas directrices estratégicas, la fijación de puntos de referencia, el establecimiento de objetivos y la puesta en marcha de un sistema de seguimiento para evaluar los progresos por medio de una revisión por grupos de pares o de homólogos. En efecto, sobre la base del análisis de la adopción de decisiones en la UE, es posible comprobar que en el MAC se abordan planes o estrategias que pretenden obtener los resultados a medio plazo, cuya intensidad aumenta en el tiempo. Este elemento doble de intensidad creciente y de evaluación periódica de la acción contiene una responsabilidad política activa y contínua en el contexto nacional de los EEMM, afectando a los progresos registrados en la puesta en ejecución de los objetivos convenidos en común (Coyne y Pierini 2001). Esto conduce a la conveniencia de examinar el contexto nacional en el cual los gobiernos actúan.

Para el colectivo Notre Europe (Collignon et al. 2004), se plantea un problema clásico de cooperación internacional: ¿Cómo procurar que los EEMM respeten sus compromisos? Está claro que las exhortaciones a la virtud o a la voluntad política serán apenas suficientes. A falta de tal enfoque, el ejercicio corre peligro de volverse poco productivo, porque paradójicamente podría animar a los gobiernos que temen una evaluación negativa de su realización, a no comprometer reformas que podrían revelarse costosas en términos políticos. Estos autores comparten el enfoque del Informe del Grupo KOK de evaluación de la Estrategia de Lisboa (2004), que defiende una mayor «alusión, mortificación y exasperación» de los EEMM, ya que la publicación regular de cuadros de clasificación de éstos en el «Informe de síntesis» de preparación del Consejo Europeo de primavera ha suscitado, de momento, poco entusiasmo. Hacer el control político más transparente y más creíble, también implica dirigir mensajes claros a los EEMM, advirtiéndoles que se deben comprometer a realizar reformas para alcanzar los objetivos fijados. Hay que darse cuenta de que a menos que se transforme en un instrumento de trabajo más eficaz, el MAC puede correr el peligro de convertirse en un mecanismo de tipo OCDE y no gozará del apoyo de la opinión pública (Grupo KOK de evaluación de la Estrategia de Lisboa 2004).

El desafío es de altura: en una lógica de convergencia de las políticas a través del conocimiento, es vital, por un lado, combatir las fracturas en la circulación de la información, la deformación y la falsificación de los re- 
sultados comparados y, por otro, asegurar la credibilidad, la coherencia y la estabilidad de las líneas directrices fijadas en el contexto europeo. En caso contrario, la flexibilidad, de la que el MAC es portador, corre peligro de transformarse en laxitud, y la evaluación en aproximación (Georgopoulos 2005).

En este sentido, la necesidad funcional de una evaluación independiente en el seno de la UE, desembocó en la concesión de poderes de vigilancia a la Comisión. Es importante reconocer que el enfoque que inspiró el MAC no puede funcionar sin una implicación fuerte de la Comisión, que juega un papel clave como catalizador de la presión por los pares, identificando muy claramente los éxitos y los fracasos de las políticas puestas en ejecución por cada Estado miembro. En sus evaluaciones, la Comisión valora la realización «cuantitativa» de los EEMM (a saber, los progresos realizados teniendo en cuenta los indicadores cuantitativos), y, además, apunta hacia una evaluación cualitativa a la luz de los objetivos subyacentes. Ahora bien, para alcanzar estos objetivos, no cabe duda de que la función que debe asumir la Comisión es relevante, pero no se puede perder de vista que el papel de «estratega» en el posicionamiento del MAC pertenece al Consejo Europeo, y se trata de una instancia política compuesta por Jefes de Estado y de Gobierno.

Pero, sobre todo el MAC es más que una simple cooperación, ya que comporta la emergencia de una dimensión propiamente europea, la intervención de instancias comunitarias y un sistema de verificación periódica, así como la puesta en marcha de un sistema de seguimiento por el benchmarking y la evaluación del progreso. Así, las instituciones comunitarias recurren, además de a los instrumentos de presupuestación y reglamentación heredados del método tradicional, a otras técnicas importadas del management. Siguiendo a Coyne y Pierini (2001), sobre la base del análisis empírico, es posible, en el marco del MAC para la coordinación de las políticas nacionales, comprobar el papel de:

- El benchmarking como elemento esencial de policy learning too (herramienta de aprendizaje) (Lundwal y Tonlinson 2002), con el peer review como mecanismo que asegura la aplicación de los procesos de coordinación de las políticas estructurales nacionales (que se dirige a subconjuntos de EEMM y se centra sobre asuntos limitados y bien precisos en el espíritu de dar a conocer y diseminar las buenas prácticas en el seno de los comités creados en cada caso).

- Una adecuada comparabilidad de los datos y una buena comprensión de los indicadores. Indicadores y referencias comunes que sean fiables y comparables en el contexto europeo, son unos elementos claves con vistas a la definición de objetivos cuantifiables, la evaluación de las realizaciones y la eficacia de la vigilancia multilateral (peer review) en los diferentes procesos de coordinación.

- La colaboración en red (networking) de las autoridades nacionales y regionales y de los actores públicos y privados como fuente de legitimidad y de eficacia en la definición de los objetivos comunes, en su ejecución de manera descentralizada por los planes de acción nacionales, así como en el benchmarking y en el intercambio de información.

- Las dotaciones presupuestarias comunitarias que pueden constituir, en un cierto número de ámbitos, un soporte significativo para la difusión de las buenas prácticas, la construcción de la confianza (confidence-building) y la convergencia hacia los objetivos convenidos. Y además de la ayuda financiera que concede la Comunidad cuando existen competencias compartidas con los EEMM (por ejemplo, a través de los fondos estructurales), las nuevas formas de coordinación de las políticas nacionales tienen un efecto importante y multiplicador de la misma dimensión europea también desde el punto de vista presupuestario, ya que movilizan y combinan los recursos colectivos con los recursos nacionales comprometidos en los planes de acción nacionales (PANs) para alcanzar los objetivos fijados.

- La transparencia, la visibilidad y la comunicación que, en este proceso de evaluación, se convierten en esenciales al permitir a las partes afectadas (stake-holders) participar activamente en la elaboración y en la selección de los indicadores apropiados, en el control del proceso de valoración, en la vigilancia de la ejecución de los diferentes planes de acción y, si es necesario, en el ejercicio de presión sobre los gobiernos nacionales. 
No obstante, hay autores para los que la utilización de «informes de evaluación» en el ámbito comunitario se considera inadaptado. Así, para Barbier, la realidad es diferente: no se produce una evaluación de las políticas según los métodos internacionales, aunque se lleven a cabo según los criterios de calidad generalmente admitidos en este ámbito. Más bien se trata, para este autor, de trabajos de investigación ya que son construidos para servir en el proceso político. Es extraño, continúa Barbier, que muchos autores consideren con cierta ligereza los documentos bautizados como «estudios de evaluación», para acoger la validez de sus conclusiones como que prueban los efectos de los planes o de las estrategias nacionales. Además, ya que se trata de planes, y no de programas, tampoco la «evaluación de programas», habitualmente utilizada en los países europeos, es adecuada. Incluso la comunicación de la Comisión Europea sobre el «examen a medio plazo» y la «evaluación del impacto», pueden reconocerse como métodos de evaluación en sentido estricto, e incluso la posibilidad de establecer lazos causales entre los «resultados» presentados por los EEMM y las estrategias establecidas en el ámbito europeo, pueden ser considerados ejercicios de evaluación (Barbier 2004).

A pesar de estas fundadas apreciaciones académicas, para quien escribe este artículo, el MAC ha demostrado ser un instrumento útil de avance, a través de la instauración de un sistema de evaluación institucional, en aquellos sectores de la política comunitaria donde no existen instrumentos de coordinación más fuertes. Opinión que comparten otros autores que consideran que el MAC, a través de ejercicios de evaluación basados en «cuadros de mando», se transforma en un instrumento de gestión eficaz para hacer que la UE progrese de manera coordinada y más rápida en aquellos ámbitos hasta ahora reservados a la competencia nacional, o relacionados con los objetivos estratégicos de la Unión (Goetschy 2004). Para esta autora, entre los actores del MAC, la Comisión juega un papel relevante de motor, de coordinación y de evaluación del conjunto de procesos. En definitiva, confrontada a una gran diversidad de intereses, la Comisión, en términos coloquiales, «dirige la orquesta», en la medida en que controla la agenda, dispone de un conocimiento interno de las complejidades institucionales y procedimentales de la UE, y encarna la «memoria histórica» frente a las presidencias turnantes y las mayorías políticas fluctuantes en los ámbitos europeo y nacional (Goetschy 2004).

No obstante, siguiendo a Dür y Mateo (2004), conviene traer a colación a Haas (1992), quien desarrolló el concepto de comunidades epistémicas definidas como redes de profesionales con reconocida pericia en un dominio o área particular. Las advocacy coalitions, estudiadas por Sabatier (1998), están compuestas por redes de políticos, representantes de grupos de interés, funcionarios, investigadores y periodistas, entre cuyas funciones está la de contribuir a diseminar las ideas que tienen su origen en la Comisión Europea y el entorno subnacional, para influir así en la definición de los intereses de los actores (Kohler-Koch 2002). Por otra parte, no se puede ignorar el rol del Consejo de la UE, en donde, sin perjuicio del papel relevante del Consejo Europeo y de las distintas formaciones del Consejo de Ministros, los EEMM delegan autoridad en los expertos y otros actores, representados en los diversos comités del Consejo, con la finalidad de encarnar las sensibilidades nacionales, encontrar regulaciones comunes y equilibrar la notable influencia de la Comisión Europea.

\subsection{Dirección por objetivos e indicadores estructurales}

Es habitual en la dirección por objetivos y en las estrategias de gestión de la calidad, el reconocimiento de que si no hay cuantificación, no puede haber comprensión; si no hay comprensión no puede haber control; y si no hay control, no puede haber mejora continua. Es por ello que cualquier documentación de soporte de verificación de planes o estrategias de políticas públicas, basadas en objetivos, ha de contener indicadores que permitan la evaluación de los resultados.

La UE no ha sido ajena a esta tendencia. La experiencia acumulada en los últimos años indica la propensión a cuantificar los esfuerzos políticos y los resultados económicos en el seno de la Unión. Se hace un uso cada vez mayor de la evaluación comparativa y de la presión mutua para la supervisión y la coordinación de políticas. Sin embar- 
go, para aprovechar completamente estos instrumentos, se hacen necesarios indicadores fiables que sean comparables a lo largo del tiempo, para todos los EEMM, para la Unión en su conjunto, así como para los países utilizados como referencia. Además, si se ha de contar con unos indicadores, éstos han de ser homogéneos, de tal modo que se puedan establecer comparaciones adecuadas entre los diversos EEMM, con vocación de mejora continua.

Así, el Consejo Europeo de Lisboa reconoció la necesidad de discutir y de evaluar regularmente los progresos hechos en la realización del objetivo estratégico de la Unión, planteado para la ocasión ya mencionado, sobre la base de indicadores estructurales comúnmente acordados. Con este fin, invitó a la Comisión «a que prepare un informe anual de síntesis sobre los progresos basado en los indicadores estructurales que deben acordarse sobre el empleo, la innovación, la reforma económica y la cohesión social» (Consejo Europeo de Lisboa de 2000; apartado 36 de las Conclusiones de la Presidencia)

En respuesta a este mandato, la Comisión (2000b) elabora un grupo de indicadores clave que deben utilizarse en el informe de síntesis posteriormente modulados por el Consejo. Para la Comisión, la motivación subyacente al uso de indicadores estructurales y al examen regular de los resultados estructurales sobre la base de indicadores cuantitativos, convenidos de común acuerdo, es esencialmente doble:

- Supervisar el avance tanto en la realización de los objetivos establecidos, como en la aplicación de políticas; y

- Evaluar la eficacia de las políticas.

Después de seis años de experiencia comunitaria, se cuenta con una lista limitada de indicadores, para los cuatro ámbitos citados en Lisboa (Cuadro 2). La ventaja de centrarse en un número reducido de indicadores es que permite a los responsables políticos el envío de mensajes sencillos y claros. El trabajo para encontrar nuevos indicadores, o para mejorar los utilizados actualmente, se realiza en el seno de los distintos grupos de trabajo de los Comités del Consejo afectados (Comité de Política Económica, Comité de Empleo y Comité de Protección Social), sobre la base de los siguientes principios: el grupo de indicadores debe ser relativamente estable en el tiempo para asegurar la continuidad, y estar basados, lo más posible, en la información proporcionada por el sistema estadístico europeo.

\section{CUADRO 2}

\section{INDICADORES ESTRUCTURALES}

- Lista restringida -

\begin{tabular}{|c|c|c|}
\hline $\begin{array}{l}\text { Situación económica general } \\
\text { 1. PIB per cápita en SPA (estandar de poder } \\
\text { de compra). } \\
\text { 2. Productividad del trabajo. }\end{array}$ & $\begin{array}{l}\text { Empleo } \\
\text { 3. Tasa de empleo. } \\
\text { 4. Tasa de empleo de los trabajadores de } \\
\text { más edad. }\end{array}$ & $\begin{array}{l}\text { Innovación investigación } \\
\text { 5. Nivel de educación (20-24). } \\
\text { 6. Gasto en I+D }\end{array}$ \\
\hline $\begin{array}{l}\text { Reforma económica } \\
\text { 7. Niveles de precios relativos. } \\
\text { 8. Inversión de las empresas. }\end{array}$ & $\begin{array}{l}\text { Cohesión social } \\
\text { 9. Índice de riesgo de pobreza. } \\
\text { 10. Dispersión de los índices de empleo } \\
\text { regional. } \\
\text { 11. Desempleo de larga duración. }\end{array}$ & $\begin{array}{l}\text { Medio ambiente } \\
\text { 12. Emisión de gases con efecto } \\
\text { invernadero. } \\
\text { 13. Intensidad energética de la economía. } \\
\text { 14. Volumen del transporte. }\end{array}$ \\
\hline
\end{tabular}

Fuente: Conclusiones del Consejo sobre indicadores estructurales (2003). 
Para preparar el Consejo Europeo de primavera, la Comisión examina los progresos realizados por los EEMM respecto a los objetivos de Lisboa,y elabora un «Informe de síntesis». Por esta razón, los indicadores estructurales pueden interpretarse en el contexto del marco analítico que dicho informe proporciona. Es decir, la elección de indicadores depende del propósito de este informe. Para algunos autores, tal enfoque incita a maquillar la realidad: en lugar de comprometer reformas importantes y duraderas, los países se esfuerzan por respetar el objetivo a corto plazo, sobreestimando a veces los resultados nacionales para obtener un mejor «resultado» (Collignon et al. 2004).

La Comisión reconoce, además, que los indicadores no son ningún sustitutivo de las evaluaciones cualitativas en profundidad. En efecto, el autor considera conveniente añadir que, además del informe de síntesis, de carácter fundamentalmente cuantitativo, en determinados ámbitos de la Estrategia de Lisboa, se realiza una evaluación, tanto cuantitativa como cualitativa, de los resultados alcanzados por el Estado miembro correspondiente en el cumplimiento de los objetivos comunes previamente acordados. En el marco de la elaboración de informes conjuntos de resultados Comisión-Consejo, para cada área, se produce un examen bilateral Comisión-Estado miembro, que, en muchos casos, conlleva un proceso de negociación, a veces nada «pacífico», y la necesidad de una justificación objetiva ante la Comisión. Habitualmente, la Comisión, en su ejercicio independiente de iniciativa, hace públicos los resultados de su informe de evaluación ante los medios de comunicación, y los «cuelga» en Internet, a veces con carácter previo al informe que hay que presentar conjuntamente con el Consejo, lo que genera mas de un sobresalto en los responsables políticos nacionales, del que el propio autor puede dar fe.

Desde la perspectiva de la transparencia y de la legitimidad, hay expertos que consideran que los indicadores utilizados tienden a reflejar más bien un consenso fácilmente establecido entre los EEMM, y no los elementos realmente percibidos por los ciudadanos como lo importante para su vida y sus aspiraciones. Conviene adoptar medidas con el fin de reforzar el carácter «abierto» del MAC con una implicación activa de las partes afectadas que son indispensables para una puesta en ejecución acertada de este método (Collignon et al. 2004). No obstante, el autor debe matizar, de nuevo, que existen ámbitos comunitarios en donde la elaboración, e incluso la evaluación, de los planes nacionales de acción, se produce con la participación de los actores afectados, los interlocutores sociales y los representantes de la sociedad civil, las entidades regionales y locales, además de los representantes gubernamentales, siendo este un asunto que provoca que la Comisión Europea esté especialmente atenta a si se ha producido, o no, la intervención adecuada de todas las partes concernidas. Realizada esta matización, compartimos con estos autores la necesidad de que los indicadores no deben ser elaborados y adoptados sin deliberación política y social, y que la focalización sobre los parámetros cuantitativos no puede descuidar, además, la dimensión cualitativa, como ya está sucediendo, por ejemplo, en la política social europea (Pérez Menayo 2005).

En definitiva, ya que existe la convicción de la necesidad de una determinada forma de acción conjunta en el contexto europeo, a través del MAC, conviene reforzar la eficacia del proceso de control. En este sentido, la comunidad política debe disponer de indicadores adecuados de resultados, pero igualmente de una evaluación creíble de los esfuerzos.

\section{Enseñanzas extraídas de la experiencia}

Para muchos autores el análisis comparativo resulta difícil dado que el MAC presenta distintos grados y formas de desarrollo en los diferentes sectores, en donde se está aplicando. Por otra parte, en muchos casos, es aún demasiado pronto para evaluar las repercusiones sobre el terreno de la aplicación del método. La naturaleza híbrida del MAC presenta puntos fuertes y débiles, como veremos a continuación. 


\subsection{Puntos fuertes}

Tanto el Grupo KOK como la Comisión Europea han observado los siguientes aspectos positivos:

- El MAC contribuye a lograr una interpretación común y un lenguaje común entre todos los EEMM en un ámbito político determinado. Ello permite determinar cuestiones y problemas comunes que después facilitan el acuerdo entre EEMM en torno a directrices de la UE y objetivos y previsiones políticas generales de la misma. En todas las experiencias en que se ha utilizado este método se ha destacado indudablemente esta ventaja.

- En algunos casos los objetivos amplios o estratégicos de la UE se han plasmado en objetivos operativos comunes bastante pormenorizados (educación y formación) u objetivos nacionales específicos cuantificados (proyecto de objetivos cuantitativos en el campo de empresa, objetivos cuantitativos para la reducción de la pobreza y la exclusión social).

- Conduce en muchos casos al establecimiento de estrategias y planes de acción nacionales coherentes con los objetivos acordados de la UE.

- Generalmente, es eficaz en el intercambio de buenas prácticas y puede dar lugar a ejercicios de evaluación comparativa efectivos con repercusiones positivas en algunos EEMM (la evaluación comparativa eEuropa basada en resultados de eEuropa 2002 tuvo un gran impacto en España con la eAdministración (eGobierno) o en Portugal con la penetración de Internet).

- Ha ayudado en algunos casos a plantear en la escena política la necesidad de acción urgente y de reforma en los EEMM (sirvan de ejemplo el primer plan de acción eEuropa 2002 y el área de inclusión social).

- Ha permitido racionalizar y simplificar diversos procesos a escala de la UE (mayor concentración de la Comisión en actividades de la sociedad de la información e integración en otras políticas sectoriales, la futura reunificación antes de 2006 de la educación y formación en un único ámbito, el programa Educación y Formación 2010), y la integración de determinadas medidas políticas en diversos ámbitos tanto en la UE como en el ámbito nacional (caso de la inclusión social y las pensiones, y próximamente la asistencia sanitaria y los cuidados de larga duración-dependencia).

Por su parte, para el Grupo sobre Gobernanza Económica de la Convención Europea (2002), aunque el MAC es sin duda un instrumento útil, considera que es necesario precisar el principio según el cual no pueda ser utilizado para reemplazar los procedimientos de reglamentación comunitaria más obligatorios, sin excluir necesariamente el MAC como complemento de las medidas. Así, este Grupo se inspira a su vez en el Grupo interservicios sobre la Gobernanza europea (Coyne y Pierini 2001), citado anteriormente, y señala que el MAC puede convertirse en una herramienta valiosa:

- Cuando el ámbito de trabajo está ligado a la identidad o a la cultura nacional y en dónde un instrumento comunitario de armonización legislativa no es apropiado (p.e. educación o cultura).

- Cuando los instrumentos de ejecución de políticas del ámbito nacional son tan diversas y complejas, que una armonización aparece como desproporcionada con relación a los objetivos a alcanzar (p.e. protección social en el ámbito europeo y Estrategia Europea para el Empleo);

- Finalmente, la coordinación puede preceder la acción comunitaria legislativa, cuando los EEMM no desean todavía una legislación común en un ámbito dónde, sin embargo, tienen la voluntad política de progresar conjuntamente (por ejemplo, asilo e inmigración). 


\subsection{Puntos débiles}

El Grupo KOK y la Comisión Europea reparan en los siguientes aspectos de mejora:

- El enfoque voluntario acaba resultando en muchos casos en una falta de compromiso de los EEMM en el proceso. Entre los ejemplos se cuentan la renuencia de los EEMM para informar sobre los avances (eEuropa o educación y formación) o para participar en ejercicios de evaluación interpares (política empresarial). En este contexto la eficacia de la emulación es muy baja. Muestra evidente de esto es el caso del MAC para aumentar la inversión en investigación, aspecto en el que los EEMM siguen siendo reacios a establecer parámetros y se retraen a aceptar análisis comparativos.

- No se ejerce control alguno sobre la manera en que los EEMM traducen los objetivos comunitarios acordados en medidas nacionales concretas, particularmente en cómo se lleva a cabo la coordinación entre los distintos niveles nacionales (regional y local), cómo se fijan los objetivos subnacionales y cómo participan los interesados. A veces la acuciante necesidad de que se involucren los interesados se siente más agudamente dentro de la UE propiamente dicha, como ya hemos apuntado, que en los EEMM.

- La no obligatoriedad de los objetivos de la UE y el carácter voluntario de los objetivos nacionales debilitan la capacidad del método para llevar a cabo los cambios estructurales necesarios. En muchos casos los EEMM pueden desarrollar políticas nacionales sin ninguna referencia a las directrices acordadas o a los objetivos estratégicos de la UE.

Por su parte el Grupo sobre Gobernanza Económica de la Convención Europea (2002), recuerda que el MAC es objeto de las siguientes críticas:

- A veces es aplicado indistintamente, con ocasión de una misma acción, a ámbitos en los cuales la Comunidad no tiene ninguna competencia y en otros en donde dispone de ésta. En consecuencia se puede producir confusión en el ejercicio de las competencias y al mismo tiempo apartar al Parlamento Europeo cuando se trata de materias comunitarias en donde su contribución está prevista por el TCE.

- Cuando el MAC, se aplica en los ámbitos en donde la Comunidad no es competente, contribuye a dar a la Comunidad una imagen de omnipotencia. Resulta un sistema falto de claridad que puede provocar la percepción en los ciudadanos de que la Comunidad es requerida para aplicar el MAC cuando éste se limite a una coordinación no vinculante y sumisa al libre albedrío de los EEMM.

- Asimismo, es necesario añadir la dificultad para identificar a los actores del método, ya que el procedimiento es puesto en la práctica en manos de Comités de alto nivel, desprovistos de legitimidad democrática, que elaboran la casi totalidad de lo que se convierte en las líneas directrices adoptadas por el Consejo Europeo. Se trata de un proceso basado en los expertos, introducido en la mecánica comunitaria en un momento en el que ésta sufre un déficit de imagen en la opinión pública.

- En cuanto a la Comisión, se registra una tendencia a proponer el MAC en numerosos ámbitos y, por tanto, por el papel relevante que esta juega, de incrementar su influencia en áreas en donde no hay competencia comunitaria, lo que expone a la Comisión a verse reprobada de intervenir más allá de sus competencias.

Por lo que se refiere al MAC como un instrumento de evaluación institucional de las políticas públicas en la UE, una vez realizado el «rodaje» del MAC en las áreas correspondientes, se coincide con aquellos autores que han identificado problemas en el funcionamiento del sistema de presión y evaluación por los homólogos o peer review. Este sistema que figura entre los instrumentos de la nueva gestión pública ha sido tomado prestado del gobierno de la empresa. Esta técnica puede ser eficaz en el ámbito empresarial, donde existe en principio una jerarquía bien definida, pero su utilización en el contexto europeo, con una cadena netamente menos evidente de 
mando, es problemática (Arrowsmith et al. 2004). La dificultad es bien conocida en el marco de las relaciones internacionales, en donde los mecanismos descentralizados de ejecución funcionan raramente en ausencia de toda forma de control (Collignon et al. 2004).

Es necesario reforzar el peer review, dado que no ha funcionado adecuadamente, en parte por el hecho de que los miembros de los Comités no desean «denunciar y mortificar» a sus homólogos. Los actores temen hacer enemigos y pagar las consecuencias negativas en otros campos políticos donde progresaron poco, o constituyen una prioridad en el plano nacional. En la mayoría de los campos que han sido objeto de un proceso MAC, comprobamos que la presión por los pares como tal era a menudo insuficiente para producir los resultados esperados, al menos a corto plazo. Además, la experiencia ha mostrado que en ciertas ocasiones, la presión por los pares podía ser suplantada por una complicidad entre pares que pretenden escapar de una disciplina convenida por acuerdo común, lo que es difícil de evitar en un sistema donde los funcionarios nacionales son a la vez evaluadores y, a su vez, son controlados (Collignon et al. 2004).

\subsection{Conclusiones}

A pesar de lo apuntado en el apartado anterior, para el autor de este artículo, el gran mérito del MAC reside en su flexibilidad y en su capacidad de contribuir a la convergencia progresiva de las políticas nacionales, en ámbitos donde las reticencias de los EEMM no permiten la integración, por lo menos en las condiciones ordinarias aseguradas por el derecho comunitario. Posiblemente, el postulado de la uniformidad del derecho comunitario ha de ser relativizado, por razones más prácticas que doctrinales. En una Europa a 27, asegurar la aplicación uniforme del derecho comunitario se revela como una tarea particularmente ardua. Incluso hay razones más poderosas que las de orden cuantitativo: las diferencias políticas, económicas, sociales, y hasta geográficas y culturales, que separan a los EEMM de hoy, son mucho más importantes que las de los seis Estados fundadores (Georgopoulos 2005: 7).

En efecto, el MAC se ha concebido como un método dúctil de buen gobierno que debe completar el «método comunitario» existente y otros procesos basados en el TCE, y que ha permitido a los EEMM desarrollar progresivamente sus propias políticas. El MAC constituye un instrumento efectivo para llegar al consenso en la UE sobre la necesidad de proceder a reformas estructurales importantes y determinar objetivos estratégicos comunes en ámbitos de políticas que son clave para alcanzar los objetivos de la Estrategia de Lisboa para el periodo 20002010. Es también un instrumento útil para intercambiar buenas prácticas y mejorar la coordinación de los EEMM.

Como ya se ha subrayado, el MAC se distingue claramente del método comunitario, basado en las enseñanzas del positivismo jurídico y de la regulación por la norma jurídica. En el MAC la regla jurídica es reemplazada por la orientación política, y la fijación de estándares, más o menos rígidos, por la experimentación, la evaluación y el conocimiento. Por consiguiente, el MAC abre la perspectiva de un nuevo paradigma científico en materia de regulación. Esto suscita ciertas interrogantes en la doctrina, que se pregunta, de manera general, por el rebasamiento de la concepción piramidal del sistema jurídico hacia una configuración en red.

Otro problema recurrente en la práctica legislativa de la UE es la rigidez del proceso de adopción de decisiones. La primera razón de esta rigidez depende del equilibrio institucional querido por los constructores de la arquitectura institucional de la Unión. El «triángulo institucional» (Comisión, Consejo, Parlamento) hace relativamente difícil la producción legislativa. A esta preocupación, hay que añadir el principal escollo en la distribución del poder en el seno de la UE, a saber las negociaciones complejas, y a veces difíciles, que disminuyen la producción normativa, o, al menos, la ralentizan. El MAC propone remediar este problema, introduciendo más flexibili- 
dad en el proceso de adopción de decisiones. El carácter ampliamente atípico, léase altamente político, de las líneas directrices adoptadas por el Consejo Europeo, deja a los EEMM, pero incluso al propio Consejo Europeo, un margen amplio de maniobra en el reajuste de estas (Smismans 2004). En efecto, la evaluación continua de las realizaciones permite readaptar no sólo las políticas nacionales sino las orientaciones europeas mismas. Así, como se trata de un proceso cognitivo, la difusión de las informaciones vinculadas a la ejecución de las políticas nacionales hace posible la evolución óptima de los parámetros planteados.

Por otra parte, el MAC abre, además, nuevas perspectivas para una mejor aprehensión de las especificidades nacionales e incluso locales. Aquí, el enfoque es inverso: en lugar de admitir excepciones en la aplicación uniforme de la reglamentación europea, se confirma la libertad de las autoridades nacionales a ejercer sus propias políticas. De esa manera, las particularidades nacionales y regionales, incluso las locales, son tenidas en cuenta a priori por las autoridades nacionales, que, por definición, están mejor situadas para conocerlas. La UE se contenta con una orientación general y con la puesta a punto de mecanismos de evaluación, de información y de control. La divisa «unidos en la diversidad « parece alcanzar todo su sentido en el marco del MAC (Georgopoulos 2005: 8). No obstante, el autor también comparte la necesidad de hacer frente a las limitaciones del MAC como instrumento de buen gobierno para llevar a cabo los cambios estructurales necesarios en el entorno nacional. Hay que procurar romper las inercias de aquellos EEMM reacios, todavía, a comprometerse con los objetivos acordados en común.

Asimismo, como ha señalado el Grupo KOK, parece oportuno un desarrollo más organizado y coordinado del MAC en las distintas políticas para asegurar su eficacia e importancia para conseguir los objetivos de Lisboa. Y, por su parte, el colectivo Notre Europe, liderado por el ex-presidente de la Comisión Europea Jacques Delors, la Estrategia de Lisboa (y el propio MAC, añadiría el autor), es en parte víctima de su propio éxito. Concebida en un momento en el que existían grandes diferencias entre las prioridades de los gobiernos nacionales, se desarrolló en cierto modo a ciegas (de nuevo la analogía de Puchala de «ciegos y elefantes» que sugeríamos al comienzo de este trabajo). Durante un cierto tiempo, pareció que toda cuestión considerada como poco importante para Europa debía estar sometida a un mecanismo del tipo MAC (el autor no comparte esta afirmación ya que entiende que en los inicios de la aplicación del MAC se eligieron por el Consejo y la Comisión, desde un punto de vista estratégico, aquellas áreas que menos resistencias podían generar en los EEMM y que, además, a nuestro parecer no pueden ser calificadas como poco importantes: sociedad de la información, investigación, educación y formación, inclusión social, a las que se han ido añadiendo otras no menos principales). Comprobamos actualmente que el número de políticas en las cuales la UE interviene jamás fue tan importante. Pero, al haber sido considerado el MAC como una suerte de panacea, el dispositivo de Lisboa ha sido sobrecargado, dando lugar a problemas importantes de coordinación, tanto entre las acciones empeñadas en los diferentes dominios políticos como entre el contexto nacional y el de la UE.

En este sentido, el autor quiere subrayar que antes de aplicar el MAC a nuevas políicas, convendría, que la Comisión Europea y sus redes de comunidades epistémicas de influencia (advocacy coalitions), cultivaran la paciencia, y así consolidar lo hasta ahora conseguido, que es mucho y relevante. De lo contrario, se podría generar una situación perjudicial para la credibilidad del MAC, cuando este aparece como la única manera realista disponible de ampliar la agenda comunitaria sobre asuntos de dominante soberanista, tradicionalmente difíciles de tratar fuera de las fronteras nacionales, en donde no hay competencia comunitaria, con una fuerte diversidad territorial en una UE ya de 27 miembros o, incluso, de 30.

De todas formas, la generalización y la flexibilidad del MAC no constituyen una panacea. Hay que esperar sus aplicaciones en el tiempo para medir su credibilidad. Ésta dependerá del buen uso de los elementos de este método prometedor. 
Finalmente, desde un punto de vista epistemológico, la evaluación fue concebida en sus orígenes sobre el modelo de los protocolos para medir la eficacia de los tratamientos médicos experimentales. Los textos americanos sobre la evaluación utilizaban frecuentemente el término «tratamiento» (treatmen), para designar el conjunto de medidas a la que son sometidos los objetivos sociales de una política (Cook 1995). Posiblemente, este paradigma pueda ser interesante para entender el rol del MAC en un momento en el que la UE está necesitada de «cuidados paliativos», sobre todo a raíz de la primera evaluación intermedia de la Estrategia de Lisboa, y algunos de los acontecimientos recientes acaecidos en torno a la no ratificación, por determinados EEMM, del proyecto de nuevo Tratado por el que se instituye una Constitución para Europa.

\section{REFERENCIAS BIBLIOGRÁFICAS Y DOCUMENTALES}

Arrowsmith, J., Marginson, P. y Sisson, K. (2002), «All Benchmarkers Now? Benchmarking and the 'europeanisation' of Industrial Relations». Documento de trabajo 41/02. Sussex: Sussex European Institute.

Barbier, J.C. (2004), «Les méthodes ouvertes de coordination dans le social et l'emploi européens: comment les aborder?». Communication au colloque du Matisse, París 16 y 17 de septiembre.

Borrás, S. y Jacobsson, K. (2004), «The open method of co-ordination and new governance patterns in the EU», Journal of European Public Policy (11) 2: 185-208.

Bruno, I., Jacquot, S. y Mandin, L. (2004), «Européanisation des politiques publiques et intégration européenne», Contribution à la journée d'études L'Européanisation saisie par son instrumentation: Benchmarking, Mainstreaming et MOC. Boite à outils ou boite de Pandore? París: Institut d'Etudes Politiques de Paris. <http://www.sciencespo.fr/recherche/forum_europeen/prepublications/Papier_3_Jacquot_Bruno_Mandin.pdf> (consulta: 6 de julio 2005).

Comisión Europea (2001a), Comunicación de la Comisión al Consejo y al Parlamento Europeo relativa a un método abierto de coordinación de la politica comunitaria en materia de inmigración. COM 387 final. Bruselas: Diario Oficial de la Unión Europea.

Comisión Europea (2001b), La gobernanza europea. Un libro blanco. COM 428 final. Bruselas: Diario Oficial de la Unión Europea.

Comisión Europea (2001c), Contribution enregistrée dans le cadre du «Debat public sur l'avenir de l'Europe .<http://www.europa.eu.int/futurum> (consulta 20 de julio 2005)

Comisión Europea (2005a), La Estrategia Europea para el empleo. <http://europa.eu.int/comm/employment_social/employment_strategy/index_fr.htm> (consulta : 15 de julio 2005).

Comisión Europea (2005b), Mise à jour de l'Annexe statistique. Annexe 1 du Rapport 2005 de la Commission au Conseil européen de Printemps Indicateurs Structurels <http://europa.eu.int/comm/eurostat/structuralindicator> (consulta : 10 de agosto 2005).

Comisión Europea (2005c), Communication de la Commission au Conseil, au Parlement européen, au Comité conomique et social européen et au Comité des Régions. Travailler ensemble, travailler mieux: Un nouveau cadre pour la coordination ouverte des politiques de protection sociale et d'inclusion sociale dans l'Union européenne. COM 706 final (No publicada en el Diario Oficial).

Consejo de la Unión Europea de Helsinki (1999), Informe del Consejo ECOFIN al Consejo Europeo de Helsinki sobre la coordinación de la politica Económica. Documento 13123/1/99 REV1.

Consejo de la Unión Europea de Lisboa (2000), La méthode owverte de coordination: un processus en cours. Nota de la Presidencia portuguesa de la Unión. Documento 9088/00.

Consejo de la Unión Europea de Barcelona (2002), Racionalización de los procesos de coordinación de las políticas. Documento $14492 / 02$. 
Consejo de la Unión Europea de Bruselas (2003), Conclusiones del Consejo sobre indicadores estructurales. Documento $15875 / 03$.

Consejos Europeos (1997-2005), Conclusiones de la Presidencia (período 2000-2006)

$<$ http://ue.eu.int/showPage.asp?id=432\&lang=es\&mode=g> (consulta: julio-agosto 2005).

Convención Europea (2002a), Informe definitivo del Grupo de Trabajo IV sobre Gobernanza económica. Documento 357/02. Bruselas.

Convención Europea (2002b), La coordination des politiques nationales: la méthode ouverte de coordination. Grupo de Trabajo VI, Documento 015. Bruselas

Convención Europea (2003a), Europe sociale. Grupo de Trabajo XI, Documento 038. Bruselas.

Convención Europea (2003b), Informe final del Grupo XI sobre la Europa Social. Documento 516/1/03 REV 1 WG XI9. Bruselas.

Convención Europea (2003c), Informe resumido de la sesión plenaria. Documento 548/03. Bruselas.

Convención Europea (2003d), Open Coordination. Grupo de Trabajo XI, Documento 03824. Bruselas.

Collignon, P. et al. (2004), La stratégie de Lisbonne et la méthode ouverte de coordination. 12 recommandations pour une stratégie à plusieurs niveaux plus efficace. París: Notre Europe.

Coyne, D. y Pierini, F. (2001), «Expertiser les processus de coordination des politiques nationales», en Comisión Europea, Livre Blanc sur la gowvernance. Chantier $n^{\circ} 4$. Cohérence et coopération dans une Europe en réseau. París: Foundation pour l'innovation politique.

Degryse C. y Pochet, P. (2000), «El probable impacto de la CIG en la política social europea», Observatoire Social Européen 3.

Dehousse R. (2003), «La méthode communautaire a-t-elle encore un avenir?», en Mélanges en Hommage à Jean-Victor Louis (vol. I). Bruselas: Editions de l'Université libre de Bruxelles.

Dehousse R. (2004), «Du bon usage de la méthode ouverte de coordination», en R Dehousse, dir., L'Europe sans Bruxelles? Une analyse de la méthode owverte de coordination. París: Logiques Politiques.

De La Rosa, S. (2005), «La place de la méthode ouverte de coordination dans la soft law communautaire. Une ressource normative en gestation?» Ponencia presentada en el congreso Présentation de la problématique présentée lors de la journée d'études de la revitalisation de la soft law en droit communautaire. Institut d'études politiques d'Aix-en-Provence, 17 y 18 de junio.

Dür A. y Mateo González, G. (2004), «¿Más hombres ciegos y más elefantes? Una revisión de la literatura más reciente sobre la integración europea». Barcelona: Departamento de Ciencia Política y Derecho Público de la Universidad Autónoma de Barcelona, Documento de trabajo 233.

Eberlein, B. y Kerwer, D. (2002), «Theorising the New Modes of European Union Governance», European Integration Online Papers 6 (5).

Georgopoulos, T. (2005), La méthode ouverte de coordination européenne: «En attendant Godot»? Reims: Institut d'etudes européennes (Universidad de Reims).

Goetschy, J. (2004), «L'apport de la méthode ouverte de coordination à l'intégration européenne», en P. Magnette ed., La grande Europe. Bruselas: Editions de l'Université de Bruxelles.

Grupo KOK de alto nivel sobre la estrategia de Lisboa (2004), Informe y documentos de trabajo del Grupo. <http://www.europa.eu.int/growthandjobs/index_fr.htm> (consulta: 11 de julio 2004).

Hass, E.B. (1992), «Special issue on epistemic communities», International Organitation 46 (1): 87-224. 
Imani, E. (2005), Méthode owverte de coordination. <http://www.e-juristes.org/> (consulta: 17 de agosto 2005).

Jacobsson, K. (2001) «Employment and Social Policy Coordination : A New System of EU Governance», documento de trabajo presentado en las conferencias Scancor workshop on Transnational Regulation and the Transformation of States. Stanford, 22 y 23 de junio.

Jacobsson K. y Vifell A. (2003), «Integration by deliberation: On the role of Committees in the Open Method of Coordination». Documento de trabajo presentado en The Forging of deliberative supranationalis in the EU, Florencia, 7 y 8 de febrero.

Knill, C. y Lenschow, A. (2003), «Modes of Regulation in the Governance of the European Union: Towards a Comprehensive Evaluation», European Integration Online Papers (7) 1.

Lundvall, B. y Tomlinson, M. (2002), «International benchmarking as a policy learning tool», en M.J. Rodrigues, dir., The New Knowledge Economy in Europe: A Strategy for International Competitiveness and Social Cohesion. Cheltenham: Edward Elgar.

Meny, Y. y Thoenig, J.C. (1989), Politiques publiques. París: PUF.

Muller P. (2000), «L'analyse des politiques publiques: vers une sociologie politique de l'action publique», Revue Française de Science Politique (50) 2: 189-208.

Pérez Menayo, V. (2003a), «El método abierto de coordinación en la UE: su aplicación a las pensiones», Noticias de la UE 222.

Pérez Menayo, V. (2003b), «La estrategia europea de protección social: el método abierto de coordinación», Foro de Seguridad Social 8-9.

Pérez Menayo, V. (2005), La calidad social, un nuevo paradigma en la UE. Madrid: Ministerio de Trabajo y Asuntos Sociales (Colección Estudios).

Perret, B. (2001), «Connaissance sociale et gouvernance - Les promesses de l'évaluation», en De Schutter et al. eds., La gouvernance dans l'Union européenne. Bruselas: Comisión Europea.

Pochet, P. (2001), «Méthode ouverte de coordination et modèle social européen». Trabajo presentado en el coloquio L'Union européenne : Marché unique, modèle social unique? / The European Union: One Market, One Social Model ? Montreal: L'institute d'etudes européennes (Universidad de Montreal), 28 y 29 de septiembre.

Poelemans, M. (2004), La sanction dans l'ordre juridique mmunautaire. Contribution à l'étude du système répressif de l'Union européenne. Bruselas: Bruylant.

Radaelli, C.M. (1999), «The Public Policy of the European Union: Whither Politics of Expertise?», Journal of European Public Policy (6) 5: 757-774.

Sabatier P. y Schlager E. (2000), «Les approches cognitives des politiques publiques: perspectives américaines», Revue Française de Science Politique (50) 2: 209-234.

Scharpf, F. (1988), «The Joint-Decision Trap: Lessons from German Federalism and European Integration», Public Administration (66) 3: 277-304.

Scharpf, F. (2000), Gobernar en Europa: ¿Eficaz y Democráticamente? Madrid: Alianza.

Snyder, F. (1994), «Soft law and institutional practice in the European Community», en M. Stephen, ed., Essays in bonour of Emile Noel. Dordrecht: Kluwer Academic Publishers.

Telò M. (2001), La méthode communautaire et les nouvelles méthodes: pour une approche offensive et cohérente. Bruselas: Editions de l'Université libre de Bruxelles.

Telò M. (2003), «La gouvernance économique et sociale et la réforme des traités - La méthode ouverte de coordination», en Mélanges en Hommage à Jean-Victor Louis (vol. I). Bruselas: Editions de l'Université libre de Bruxelles.

Zeitlin J. y Pochet, P. (2005) eds., The Open Method of Coordination in Action: The European Employment and Social Inclusion Strategies. Bruselas: Peter Lang. 


\section{Experiencias y Casos}

